\title{
Cooked navy and black bean diets improve biomarkers of colon health and reduce inflammation during colitis
}

\author{
Claire Zhang ${ }^{1,2}$, Jennifer M. Monk ${ }^{1,2}$, Jenifer T. Lu ${ }^{1,2}$, Leila Zarepoor ${ }^{1,2}$, Wendy Wu ${ }^{1}$, Ronghua Liu ${ }^{1}$, \\ K. Peter Pauls ${ }^{3}$, Geoffrey A. Wood ${ }^{4}$, Lindsay Robinson ${ }^{2}$, Rong Tsao ${ }^{1}$ and Krista A. Power ${ }^{1,2 *}$ \\ ${ }^{1}$ Guelph Food Research Centre, Agriculture and Agri-Food Canada, 93 Stone Road West, Guelph, ON, Canada N1G 5C9 \\ ${ }^{2}$ Department of Human Health and Nutritional Sciences, University of Guelph, Guelph, ON, Canada N1G 2W1 \\ ${ }^{3}$ Department of Plant Agriculture, University of Guelph, Guelph, ON, Canada N1G 2W1 \\ ${ }^{4}$ Department of Pathobiology, University of Guelph, Guelph, ON, Canada N1G 2W1
}

(Submitted 23 July 2013 - Final revision received 4 December 2013 - Accepted 9 December 2013 - First published online 13 February 2014)

\section{Abstract}

Common beans contain non-digestible fermentable components (SCFA precursors) and phenolic compounds (phenolic acids, flavonoids and anthocyanins) with demonstrated antioxidant and anti-inflammatory potential. The objective of the present study was to assess the in vivo effect of cooked whole-bean flours, with differing phenolic compound levels and profiles, in a mouse model of acute colitis. C57BL $/ 6$ mice were fed a $20 \%$ navy bean or black bean flour-containing diet or an isoenergetic basal diet (BD) for 2 weeks before the induction of experimental colitis via $7 \mathrm{~d}$ dextran sodium sulphate (DSS, $2 \%(\mathrm{w} / \mathrm{v})$ in the drinking-water) exposure. Compared with the BD, both bean diets increased caecal SCFA and faecal phenolic compound concentrations $(P<0 \cdot 05)$, which coincided with both beneficial and adverse effects on colonic and systemic inflammation. On the one hand, bean diets reduced mRNA expression of colonic inflammatory cytokines (IL-6, IL-9, IFN- $\gamma$ and IL-17A) and increased anti-inflammatory IL-10 $(P<0 \cdot 05)$, while systemically reduced circulating cytokines (IL-1 $\beta$, TNF $\alpha$, IFN $\gamma$, and IL-17A, $P<0.05)$ and DSS-induced oxidative stress. On the other hand, bean diets enhanced DSS-induced colonic damage as indicated by an increased histological injury score and apoptosis (cleaved caspase-3 and FasL mRNA expression) $(P<0 \cdot 05$ ). In conclusion, bean-containing diets exerted both beneficial and adverse effects during experimental colitis by reducing inflammatory biomarkers both locally and systemically while aggravating colonic mucosal damage. Further research is required to understand the mechanisms through which beans exert their effects on colonic inflammation and the impact on colitis severity in human subjects.

Key words: Colitis: Inflammation: Black beans: Navy beans: Colon health: Dextran sodium sulphate: SCFA

It is becoming increasingly evident that many human chronic diseases are linked to the health of the gastrointestinal tract. Gut health is characterised by many factors including a functioning intact gut barrier, a balanced gut microbiota composition, and absence of diseases such as inflammatory bowel disease (IBD) and colon cancer ${ }^{(1)}$. Maintaining a healthy gut involves a symbiotic relationship between the gut microbiota and the host immune system, thereby preserving the integrity of the intestinal barrier and minimising inappropriate inflammatory responses ${ }^{(1,2)}$. Dysfunction or imbalances in gut health lead to chronic human diseases, such as IBD, obesity, colon cancer, diabetes and neurological disorders $^{(3-6)}$. Therefore, finding methods to maintain gut health in healthy individuals and re-establishing gut health in diseased individuals are of current interest.
Common beans (Phaseolus vulgaris) are a type of pulse crop with a long history of human health benefits, including gut health ${ }^{(7-9)}$. Specifically, beneficial changes in the gut microbiota profile and activity ${ }^{(10-12)}$, as well as reduced risk of colon cancer in humans and experimental models ${ }^{(13-18)}$, have been reported to be associated with bean consumption. Beans contain an array of bioactive components, namely fermentable non-digestible components and phenolic compounds, which may play a role in the gut health-promoting potential of beans ${ }^{(19-21)}$. Major bean components, non-starch polysaccharides, resistant starches and oligosaccharides, are fermented by the microbiota in the large intestine generating SCFA: acetate; propionate; butyrate ${ }^{(11,12)}$. Butyrate exerts direct effects on colon health as it is an important energy source for colonocytes enabling proper growth and function

Abbreviations: BB, black bean; BD, basal diet; BW, body weight; $C x c l$, chemokine (C-X-C motif) ligand; DAI, disease activity index; DSS, dextran sodium sulphate; FRAP, ferric reducing antioxidant power; GPx, glutathione peroxidase; IBD, inflammatory bowel disease; IFN- $\gamma$, interferon- $\gamma$; MPO, myeloperoxidase; NB, navy bean; ORAC, oxygen radical absorbance capacity. 
of the epithelium ${ }^{(22-24)}$, supports healthy commensal bacterial growth $^{(25)}$, increases mucus secretion via the stimulation of Muc2 (mucin 2) expression ${ }^{(26)}$, and exerts anti-inflammatory effects, in part, through the modulation of inflammationrelated cell signalling pathways and enhancement of gut barrier integrity ${ }^{(23,24,27-32)}$. Phenolic compounds present in common beans are also known to induce an array of biological effects, including reduction of colon cancer growth $^{(17,33-36)}$ and oxidative stress ${ }^{(37,38)}$, attenuation of immune responses ${ }^{(38-42)}$, enhancement of gut barrier integrity $^{(43,44)}$, and modulation of the microbiota community structure and activity ${ }^{(33,45-47)}$. Therefore, with the diverse gut modulatory effects of bioactives, gastrointestinal diseases, in addition to colon cancer, may also be beneficially modulated by common beans.

Inflammation plays a major role in the development of a number of colon-associated diseases, including IBD and colon cancer ${ }^{(48,49)}$. Colitis is a form of IBD associated with microbiota dysbiosis ${ }^{(50-54)}$, elevated oxidative stress $^{(55-58)}$, compromised gut barrier integrity and function (permeability, tight-junction protein expression, Toll-like receptor signalling, anti-microbial peptide production and goblet cell function $)^{(59-63)}$, and defects in the intestinal immune and inflammatory responses (NF- $\mathrm{B}$ signalling, cytokine expression and immune cell infiltration $)^{(59,64)}$. Current therapeutic interventions, including anti-inflammatory agents, immunosuppressants and antibiotics, aim to reduce inflammation during disease relapse and promote disease remission ${ }^{(65-67)}$. However, patients often suffer from side effects, fail to respond and also become resistant to these therapies ${ }^{(68,69)}$. Therefore, alternative or complementary therapies, including dietary components, are being studied for their effectiveness in reducing colitis symptoms and disease progression ${ }^{(70-73)}$.

Therefore, the primary objective of the present study was to examine the gut health-promoting potential of cooked common beans (i.e. consumption of the whole food rather than individual bioactives) in experimental colitis in mice. Although the effects of beans on colitis have not been studied previously, increased consumption of either fermentable non-digestible components or SCFA has been reported to reduce inflammation in both IBD patients and animal colitis models ${ }^{(29,74-80)}$. Furthermore, consumption of pure phenolic compounds or phenolic-rich food extracts has been shown to attenuate disease biomarkers through reduction of colonic oxidative stress, reducing immune cell infiltration, modulating $\mathrm{NF}-\kappa \mathrm{B}$ activation and reducing the secretion of pro-inflammatory cytokines ${ }^{(40-42,81-83)}$. In addition, two bean varieties with striking differences in their seed coat colour (navy and black beans) were utilised in the present study. Flavonoids, including flavonols, anthocyanins and tannins are largely responsible for the different pigmentations observed in beans ${ }^{(84)}$, and generally darker beans have more diverse flavonoid profiles at higher concentrations compared with the light-coloured beans ${ }^{(21,85,86)}$. Therefore, by comparing the effects of these varieties, a secondary objective was to determine whether bean phenolic profiles affect the colitis phenotype.

\section{Materials and methods}

\section{Preparation of bean flours and diets and experimental design}

Navy beans (ACUG 10-B2) and black beans (ACUG 10-6) were provided by Dr Ali Navabi, University of Guelph, Bean Breeding Program. Whole beans were soaked overnight in $250 \mathrm{ml}$ of distilled water at room temperature and cooked in a slow cooker (Hamilton Beach) on high with $0 \cdot 3 \%(\mathrm{w} / \mathrm{v})$ baking powder (Kraft Canada, Inc.) for $7 \mathrm{~h}$. Cooked beans and the remaining cooking water were homogenised, and the resulting bean paste was freeze-dried by the Guelph Food Technology Centre (Guelph) to produce bean flour. Proximate analyses and analyses of the crude fibre content of bean flours were carried out by Maxxam Analytics (Table S1, available online). In the present study, three isoenergetic experimental diets were used: basal diet (BD); BD supplemented with 20\% navy bean (NB) flour; BD supplemented with $20 \%$ black bean (BB) flour, which were prepared by Harlan Laboratories in accordance with the AIN-93G diet formulation with $5 \%$ maize oil being substituted for 5\% soyabean oil, and cellulose content increased from 5 to $7 \%$, to ensure that the total dietary fibre content was equal across the diets (Table 1). The soluble fibre contents of the BD, NB diet and BB diet were analysed by Maxxam Analytics and determined to be $0 \cdot 4,0 \cdot 8$ and $1.5 \mathrm{~g} / 100 \mathrm{~g}$ dry weight, respectively.

All experimental procedures were approved by the institutional animal care committee (University of Guelph; Animal Use Protocol\# 10R067) in accordance with the guidelines of the Canadian Council of Animal Care. Male C57BL/6 mice aged 5 weeks were purchased from Charles River, housed three to four mice per cage under controlled conditions (temperature: $23 \pm 2{ }^{\circ} \mathrm{C}$; humidity: $30 \pm 5 \%$; light: $12 \mathrm{~h}$ light $-12 \mathrm{~h}$ dark cycle) and acclimatised for 1 week with free access to the $\mathrm{BD}$ and water. Mice were assigned to one of the three dietary groups ( $\mathrm{BD} n 26, \mathrm{NB} n 13$ and $\mathrm{BB} n 13$ ) such that the group mean body weights (BW) were similar $(P>0.05)$ and were fed these diets for 2 weeks during which food intake and BW were recorded. After 2 weeks,

Table 1. Diet composition*

\begin{tabular}{|c|c|c|c|}
\hline \multirow[b]{2}{*}{ Ingredients ( $\mathrm{g} / \mathrm{kg}$ diet) } & \multicolumn{3}{|c|}{ Diets } \\
\hline & $\mathrm{BD}$ & NB & BB \\
\hline Bean flour & 0 & 200 & 200 \\
\hline Casein & 200 & 146 & 141 \\
\hline L-Cystine & 3.0 & 3.0 & 3.0 \\
\hline Maize starch & 378 & 284 & 284 \\
\hline Maltodextrin & 132 & 132 & 132 \\
\hline Sucrose & 100 & 100 & 100 \\
\hline Maize oil & $70 \cdot 0$ & $66 \cdot 0$ & $67 \cdot 0$ \\
\hline Cellulose & $70 \cdot 0$ & $21 \cdot 4$ & $25 \cdot 4$ \\
\hline Mineral mix (AIN-93G-MX) & $35 \cdot 0$ & $35 \cdot 0$ & $35 \cdot 0$ \\
\hline Vitamin mix (AIN-93-VX) & $10 \cdot 0$ & $10 \cdot 0$ & $10 \cdot 0$ \\
\hline Choline bitartrate & 2.5 & 2.5 & 2.5 \\
\hline TBHQ & 0.014 & 0.014 & 0.014 \\
\hline
\end{tabular}


fresh faecal samples were snap-frozen and stored at $-80^{\circ} \mathrm{C}$ for later analysis of phenolic content and antioxidant activity. Experimental colitis was induced by administering $2 \%(\mathrm{w} / \mathrm{v})$ dextran sodium sulphate (DSS; molecular weight 3600050000 ; MP Biomedicals) in the drinking-water for $7 \mathrm{~d}$. Half of the mice in the BD group ( $n$ 13) were given DSS-free drinking-water and served as controls. All mice were allowed free access to food and water ad libitum throughout the study period.

During DSS exposure, food intake and water consumption were monitored. Additionally, mice were monitored daily for disease activity index (DAI), assessed by measuring BW, stool consistency and blood content in the stool. BW loss was calculated as the percentage difference compared with BW at the start of DSS exposure. Stool consistency and stool blood content were measured in fresh faecal samples using the scoring system summarised in Table S2 (available online). Beckman Coulter Hemoccult Sensa test (Fisher Scientific) was used to detect occult blood. Scores for BW loss percentage, stool consistency and stool blood were each on a scale from 0 to 3 , with 0 representing the normal/healthy condition and 3 representing the worst disease outcome.

All mice were killed on day 7 of DSS exposure by cervical dislocation, blood was collected by cardiac puncture and serum was stored at $-80^{\circ} \mathrm{C}$. Colons were excised (from the caeco-colonic junction to the rectum), measured for length, weighed and flushed before removing $0.5 \mathrm{~cm}$ sections of the proximal and distal colon, which were snap-frozen in liquid $\mathrm{N}_{2}$ and stored at $-80^{\circ} \mathrm{C}$. The remaining colon was Swiss-rolled and fixed in $10 \%$ buffered formalin solution for later histological analysis. Spleen, caecum and caecal contents were also weighed and stored at $-80^{\circ} \mathrm{C}$.

\section{Colon histopathology and immunohistochemistry}

Paraffin-embedded colon Swiss rolls were sectioned $(5 \mu \mathrm{m})$ and stained with haematoxylin and eosin or Alcian blue/ Nuclear Fast Red for histological scoring of colitis severity. From the proximal to the distal colon, a crypt erosion score (1-6) and a goblet cell/mucin depletion score (1-6) were assigned using haematoxylin and eosin- or Alcian blue/ Nuclear Fast Red-stained sections, respectively (see Table S3 (available online) for a description of the scoring system). Each score was then multiplied by the percentage of colon area affected, such that the most damaged colon would have a maximum score of 600 . The final histological score was obtained by averaging the above crypt erosion and goblet cell depletion scores. All colon sections were viewed (200-400X magnification) and scored blindly using a BX51 microscope (Olympus Canada, Inc.) equipped with an Olympus DP72 Digital Camera system, and the scoring system was developed in consultation with a veterinary pathologist (G. A. W.). This scoring method was also validated by correlating the scores with colonic myeloperoxidase (MPO) levels and colon weight:length ratio, which are well-known biomarkers of colonic inflammation ${ }^{(87,88)}$.

To determine the level of apoptosis within the colon epithelium of DSS-exposed mice ( $n 7-8$ per dietary group), immunohistochemistry was performed using the active caspase-3 antibody (cleaved caspase-3 (ASP175) (\#9661); Cell Signaling Technology). Briefly, formalin-fixed, paraffinembedded sections of colon Swiss rolls were deparaffinised in xylene and rehydrated in graded ethanol, and antigens were retrieved in $10 \mathrm{~mm}$-citrate buffer ( $\mathrm{pH} \mathrm{6.0)}$ in a microwave for $15 \mathrm{~min}$. The sections were incubated in a solution of $3 \%$ $\mathrm{H}_{2} \mathrm{O}_{2}$ for $10 \mathrm{~min}$ to inhibit endogenous peroxidase activity. The sections were then blocked with $5 \%$ normal goat serum in Tris-buffered saline with Tween-20 for $1 \mathrm{~h}$ at room temperature. Primary antibody (1:300) was prepared in SignalStain Antibody Diluent (\#8112) (Cell Signaling Technology) and added to the sections overnight at $4^{\circ} \mathrm{C}$ in a humidified chamber. Washed sections were then treated with the SignalStain Boost IHC Detection Reagent (HRP, Rabbit) \#8114 (Cell Signaling Technology) for $30 \mathrm{~min}$ in a humidified chamber, followed by treatment with a liquid diaminobenzidine + substrate chromogen system (Dako Canada) for $3.5 \mathrm{~min}$. The sections were counterstained with haematoxylin, dehydrated and coverslipped using Permount (Fisher Scientific). Negative control sections were treated the same as described above, except primary antibody was replaced with antibody diluent.

For the quantification of apoptosis, the sections were viewed blindly (400× magnification) using a BX51 microscope (Olympus Canada, Inc.) equipped with an Olympus DP72 Digital Camera system. The numbers of positive cells (brown staining) were counted throughout the entire colon, which was further divided into the proximal and mid-distal colon sections. Furthermore, apoptosis within areas showing intact crypt architecture was quantified separately from apoptosis within areas identified as ulcers (no crypt architecture remaining). The length of the entire colon, as well as that of the proximal and mid-distal colon, was measured, and apoptosis is expressed as the number of positive cells $/ \mathrm{mm}$ colon.

\section{Colonic myeloperoxidase and glutathione peroxidase assays}

Distal colon tissue samples were homogenised in a lysis buffer (200 $\mu \mathrm{l} / 10 \mathrm{mg}$ colon) containing $28 \mu \mathrm{g}$ aprotinin/ml, $1 \mu \mathrm{g}$ leupeptin/ml and $1 \mathrm{~mm}$-phenylmethanesulfonyl fluoride in a Tris buffer with $10 \%$ glycerin and $5 \mathrm{~mm}$-EDTA, and the protein concentration of each sample was determined using a colorimetric Bio-Rad protein assay (Bio-Rad). Colonic MPO levels were measured by ELISA (Hycult Biotech) following the manufacturer's instructions, and the final values were corrected for protein concentration. Glutathione peroxidase (GPx) activity in colon lysates was measured using the Chemical GPx Kit (Cayman Chemical) as per the manufacturer's instructions, and enzyme activity is expressed as GPx units/mg protein.

\section{Serum cytokine analysis}

Serum concentrations of IL-10, IL-1 $\beta$, IL-6, IL-17A TNF- $\alpha$ and interferon- $\boldsymbol{\gamma}$ (IFN- $\boldsymbol{\gamma}$ ) were simultaneously assayed using the Bio-PlexPro Assay (Bio-Rad). All samples were run in 
duplicate using the Bio-Plex 200 System (Bio-Rad) according to the manufacturer's instructions.

\section{Colonic mRNA expression analysis}

Proximal colon RNA was isolated by TRIzol/chloroform extraction and purified using the RNeasy kit (Qiagen). Samples were DNase treated using the RNase-Free DNase kit (Qiagen), and RNA quality was assessed using Experion RNA Analysis Kits (Bio-Rad). Total RNA $(1 \mu \mathrm{g})$ was converted to complementary DNA using the $\mathrm{RT}^{2}$ First Strand Kit (Qiagen), and quantitative real-time PCR was carried out on the ViiA7 Real-Time PCR System (Life Technologies) using the Mouse Inflammatory Response and Autoimmunity PCR Arrays (PAMM-077Z, Qiagen). Data were analysed using the $\Delta \Delta C_{\mathrm{T}}$ method to determine the expression level of each transcript normalised to that of the housekeeping genes provided on the arrays. All data were normalised to the relative expression level of each gene of interest in healthy mice that consumed the BD.

\section{Caecal SCFA analyses}

The concentrations of caecal SCFA (acetate, propionate and butyrate) were determined by GC as described by Sugawara \& Miyazawa ${ }^{(89)}$ with slight modifications. Caecal contents were first freeze-dried, and after homogenisation ${ }^{(89)}$, the resultant supernatant was filtered through a $0 \cdot 2 \mu \mathrm{m}$ polyvinylidene difluoride filter (Chromatographic Specialties Inc.), and $1 \mu \mathrm{l}$ of the filtrate was used for injection into the GC system (Hewlett Packard 5890 Series II) using J \& W GC columns (CP WAX 52 CB $30 \times 0.53$ (1.0); Agilent Technologies). Injector and detector temperatures were maintained at 240 and $280^{\circ} \mathrm{C}$, respectively. The oven temperature, after an initial period of $1 \mathrm{~min}$ at $75^{\circ} \mathrm{C}$, was increased to $180^{\circ} \mathrm{C}$ at a rate of $6^{\circ} \mathrm{C} / \mathrm{min}$, then increased by $10^{\circ} \mathrm{C} / \mathrm{min}$ and held at $230^{\circ} \mathrm{C}$ for $6 \mathrm{~min}$. The final oven temperature was increased by $2^{\circ} \mathrm{C} / \mathrm{min}$ and kept at $240^{\circ} \mathrm{C}$ for $5 \mathrm{~min}$. The peaks were identified by comparing their retention times with acetate, propionate and butyrate GC standards (Sigma-Aldrich). Data collection was managed using the HPCHEM software developed by Agilent Technologies.

\section{Phenolic compound extraction}

Total phenolics were extracted from the NB and $\mathrm{BB}$ flours and all the three experimental diets ( $1 \mathrm{~g}$ ) using the microwave-assisted extraction method ${ }^{(90)}$. The supernatant from the $\mathrm{NB}$ and $\mathrm{BB}$ flour phenolic extracts $(2 \mathrm{ml})$ was hydrolysed with $1 \mathrm{ml}$ of $6 \mathrm{M}-\mathrm{HCl}$ at $85^{\circ} \mathrm{C}$ for $2 \mathrm{~h}$ for later anthocyanin profile determination (Fig. S1, available online). Faecal phenolic compounds were extracted as described by Espín et al. ${ }^{(91)}$.

\section{Total phenolic content and total flavonoid content assays}

The Folin-Ciocalteu method was used to determine the total phenolic content in both diet and faecal extracts as described by Li et al. ${ }^{(92)}$, and it is expressed as mg gallic acid equivalents per sample $(\mathrm{g})$. Total flavonoid content in diet and faecal extracts was determined using a colorimetric method as described by Zhishen et al. ${ }^{(93)}$ with slight modifications. Briefly, $100 \mu \mathrm{l}$ of catechin $(0-100 \mathrm{mg} / \mathrm{l})$ or sample extracts were added to a $2 \mathrm{ml}$ microcentrifuge tube containing $400 \mu \mathrm{l}$ of double-distilled water and $30 \mu \mathrm{l}$ of $0.75 \mathrm{M}-\mathrm{NaNO}_{2}$. After $5 \mathrm{~min}, 30 \mu \mathrm{l}$ of $0.75 \mathrm{M}-\mathrm{AlCl}_{3}$ were added, followed by the addition of $200 \mu \mathrm{l}$ of $1 \mathrm{~m}-\mathrm{NaOH} 1 \mathrm{~min}$ later. The mixtures were diluted with $240 \mu \mathrm{l}$ of double-distilled water and vortexed, and absorbance was read at $510 \mathrm{~nm}$ using a microplate reader (PowerWave XS2; BioTek). Total flavonoid content is expressed as $\mathrm{mg}$ catechin equivalents per sample $(\mathrm{g})$.

\section{Antioxidant activity assay}

Antioxidant activity was measured using the ferric reducing antioxidant power (FRAP) and oxygen radical absorbance capacity (ORAC) assays as described elsewhere ${ }^{(92)}$.

\section{Statistical analyses}

All data were analysed by one-way ANOVA (main effect: diet) with the exception of food intake, BW and BW change percentage, which were analysed by two-way ANOVA (main effects: diet and time). The Student-Newman-Keuls, leastsquares means or Dunn non-parametric tests were used for all post hoc analyses. Differences were considered significant with $P<0.05$, and all values are expressed as means with their standard errors. Pearson's correlation analyses were carried out to examine the relationship between histological scores and colonic MPO activity or colon weight:length ratio. Statistical analyses were carried out using GraphPad Prism 5.0 (GraphPad Software, Inc.), Sigma Plot 12.0 (Systat Software, Inc.) and SAS system (SAS Institute) for Windows (version 9.0).

\section{Results}

\section{Phenolic content, antioxidant activity and anthocyanin} profile

Phenolic content in both the experimental diets and mouse faecal samples collected before DSS exposure was determined. The BB diet and BB group faecal samples had the highest phenolic content (total phenolic content and total flavonoid content) and antioxidant activity (FRAP and ORAC), followed by the NB diet and NB group faecal samples and then the $\mathrm{BD}$ and $\mathrm{BD}$ group faecal samples, which had the lowest values in all measurements (Table 2). Although ORAC was undetectable in the BD, faecal samples collected from the $\mathrm{BD}$ group exhibited a detectable ORAC, possibly due to the presence of other faecal or microbiota-derived phenolic compounds. The anthocyanin profile of both the $\mathrm{NB}$ and $\mathrm{BB}$ flours revealed five anthocyanin compounds (delphinidin, cyaniding, petunidin, pelargonidin and malvinidin; Fig. S1, available online), which were identified only in the BB flour. 
Table 2. Phenolic compound content (total phenolic content (TPC) and total flavonoid equivalents (TFC)) and antioxidant activity (ferric reducing antioxidant power (FRAP) and oxygen radical absorbance capacity (ORAC)) in the diet and mouse faecal extracts

(Mean values with their standard errors) ${ }^{\star}$

\begin{tabular}{|c|c|c|c|c|c|c|}
\hline \multirow[b]{2}{*}{ Assays } & \multicolumn{2}{|c|}{$\mathrm{BD}$} & \multicolumn{2}{|c|}{ NB } & \multicolumn{2}{|c|}{ BB } \\
\hline & Mean & SEM & Mean & SEM & Mean & SEM \\
\hline \multicolumn{7}{|c|}{ TPC (mg GAE/g) } \\
\hline Diet & $0.13^{c}$ & 0.0 & $0.24^{\mathrm{b}}$ & 0.0 & $0.56^{\mathrm{a}}$ & 0.0 \\
\hline Faeces & $0.48^{\mathrm{C}}$ & 0.03 & $0.65^{\mathrm{b}}$ & 0.02 & $0.96^{a}$ & 0.08 \\
\hline \multicolumn{7}{|c|}{ TFC (mg CE/g) } \\
\hline Diet & $0.00^{c}$ & 0.00 & $0.02^{b}$ & 0.00 & $0 \cdot 10^{a}$ & 0.004 \\
\hline Faeces & $0 \cdot 13^{c}$ & 0.01 & $0.28^{b}$ & 0.01 & $0.32^{a}$ & 0.02 \\
\hline \multicolumn{7}{|c|}{ FRAP $(\mu \mathrm{M}-\mathrm{AAE} / \mathrm{g})$} \\
\hline Diet & $0 \cdot 10^{C}$ & 0.01 & $0.75^{\mathrm{b}}$ & 0.03 & $2 \cdot 98^{\mathrm{a}}$ & 0.2 \\
\hline Faeces & $1.57^{\mathrm{C}}$ & 0.1 & $2 \cdot 05^{\mathrm{b}}$ & 0.1 & $3 \cdot 75^{a}$ & 0.3 \\
\hline \multicolumn{7}{|c|}{ ORAC ( $\mu \mathrm{M}-\mathrm{TE} / \mathrm{g})$} \\
\hline Diet & $0.0^{c}$ & 0 & $21^{\mathrm{b}}$ & 2 & $28^{\mathrm{a}}$ & 2 \\
\hline Faeces & $41^{\mathrm{c}}$ & 4 & $71^{\mathrm{b}}$ & 7 & $128^{a}$ & 11 \\
\hline
\end{tabular}

$\mathrm{BD}$, basal diet; NB, navy bean; BB, black bean; GAE, gallic acid equivalents; $\mathrm{CE}$, catechin equivalents; AAE, acetic acid equivalents; TE, Trolox equivalents.

a,b,c Mean values within a row with unlike superscript letters were significantly different $(P<0.05)$.

* For the diet analysis, $n 3$ per dietary group; for the faecal analysis, $n 6-8$ per dietary group.

\section{Dextran sodium sulphate-induced colitis disease activity index}

Before DSS exposure, there was no difference in food intake or BW between the dietary groups $(P>0.05$; Table S3, available online). During DSS exposure, mice continuously reduced their intake of food and water compared with the BD-fed healthy control mice; however, there were no significant differences between the DSS-exposed groups (Fig. 1). Throughout the DSS exposure period, mice were monitored daily for phenotypic changes (BW loss, stool consistency and stool blood content), which collectively comprise the DAI score (Fig. 1). After $1 \mathrm{~d}$ of DSS exposure, all the dietary groups exhibited an increased DAI score compared with the healthy age-matched control mice $(\mathrm{DAI}=0)$, but there were no differences between the DSS-treated dietary groups. Only on day 3 of DSS exposure, the BB + DSS group exhibited an improved DAI score compared with the NB + DSS group; however, it still did not differ from the BD + DSS group $(P<0 \cdot 05)$. At all the other time points throughout the DSS exposure period, there was no difference in DAI scores between the DSS-treated dietary groups.

\section{Caecal SCFA concentrations}

There was a reduction in caecal weight (tissue + caecal contents) in the $\mathrm{BD}+\mathrm{DSS}$ group compared with that in both the BDfed group and the NB diet-fed and BB diet-fed DSS-treated groups (Table 3). Analysis of caecal contents revealed that DSS exposure (BD + DSS) reduced the total SCFA concentrations relative to the $\mathrm{BD}$-alone dietary treatment, and this was attenuated by both the NB and BB diets, which had increased total SCFA concentrations (Table 3). Analysis of the specific SCFA species revealed that both bean diets significantly increased caecal acetate, propionate and butyrate concentrations relative to both the BD + DSS and BD-alone dietary treatments $(P<0 \cdot 05$; Table 3$)$.
Colon histology and biomarkers of immune cell infiltration and oxidative stress

Phenotypic changes in colon size (i.e. increased colon weight: length ratios) were apparent in all the DSS-treated mice compared with the healthy control mice (Fig. 2), which were further increased in mice that consumed the beancontaining diets compared with those in the BD+DSS
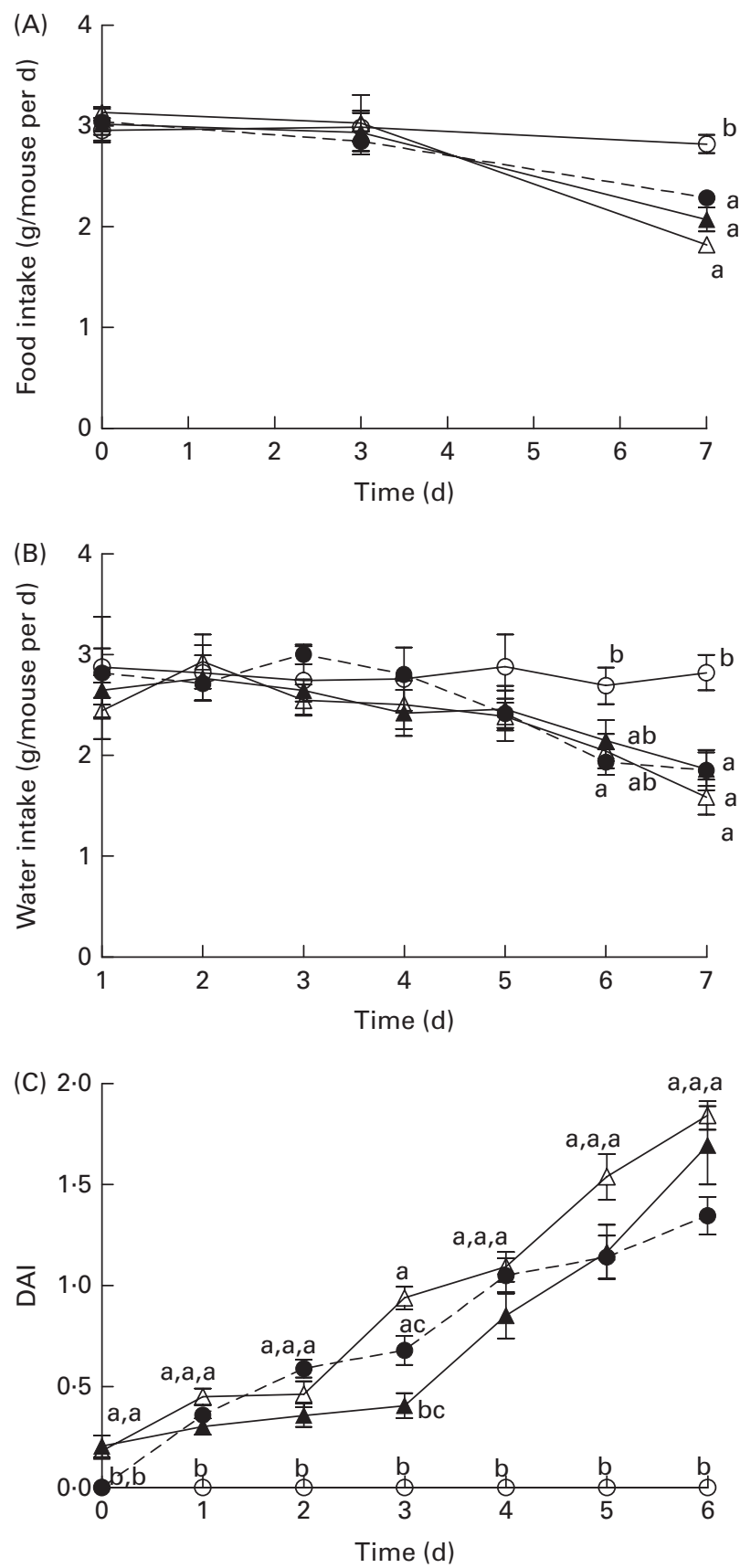

Fig. 1. Time course $(7 d)$ of changes in $(A)$ food intake, $(B)$ water intake and $(C)$ the disease activity index (DAI) score in healthy mice fed the BD $(O)$ and colitic mice fed the BD + DSS $(\bullet)$, NB + DSS $(\Delta)$ and BB + DSS $(\boldsymbol{\Delta})$ diets. Values are means ( $n 13$ per dietary group), with their standard errors represented by vertical bars. ${ }^{a, b, c}$ Mean values with unlike superscript letters were significantly different at each time point (day of DSS exposure) $(P<0.05$ Kruskal-Wallis test followed by Dunn's multiple comparison test). BD, basal diet; NB, navy bean; BB, black bean; DSS, dextran sodium sulphate. 
Table 3. Effect of the bean diets on caecal weight and SCFA concentrations in colitic mice (Mean values with their standard errors; $n 13$ per dietary group)

\begin{tabular}{|c|c|c|c|c|c|c|c|c|}
\hline & \multicolumn{2}{|c|}{$\mathrm{BD}$} & \multicolumn{2}{|c|}{$B D+D S S$} & \multicolumn{2}{|c|}{$\mathrm{NB}+\mathrm{DSS}$} & \multicolumn{2}{|c|}{$\mathrm{BB}+\mathrm{DSS}$} \\
\hline & Mean & SEM & Mean & SEM & Mean & SEM & Mean & SEM \\
\hline Caecal weight (q) & $0.21^{a}$ & 0.01 & $0.12^{b}$ & 0.005 & $0 \cdot 17^{\mathrm{a}, \mathrm{b}}$ & 0.02 & $0.19^{a}$ & 0.02 \\
\hline Acetate $(\mu \mathrm{mol} / \mathrm{g} \mathrm{DW})$ & $73 \cdot 27^{\mathrm{b}, \mathrm{c}}$ & $7 \cdot 02$ & $25 \cdot 21^{c}$ & $8 \cdot 52$ & $163 \cdot 3^{a}$ & $23 \cdot 32$ & $154 \cdot 7^{\mathrm{a}, \mathrm{b}}$ & $16 \cdot 08$ \\
\hline Propionate $(\mu \mathrm{mol} / \mathrm{g} \mathrm{DW})$ & $17 \cdot 23^{b}$ & $1 \cdot 77$ & $4.41^{c}$ & $1 \cdot 33$ & $36 \cdot 19^{a}$ & 2.95 & $38 \cdot 36^{a}$ & 4.33 \\
\hline Butyrate $(\mu \mathrm{mol} / \mathrm{g} \mathrm{DW})$ & $20 \cdot 65^{b}$ & $2 \cdot 36$ & $4.50^{\mathrm{C}}$ & $1 \cdot 7$ & $29 \cdot 09^{a}$ & $2 \cdot 18$ & $31 \cdot 61^{a}$ & 3.74 \\
\hline Total SCFA $(\mu \mathrm{mol} / \mathrm{g}$ DW $)$ & $111 \cdot 1^{\mathrm{b}}$ & $10 \cdot 73$ & $34 \cdot 11^{c}$ & 11.5 & $228 \cdot 6^{a}$ & $27 \cdot 27$ & $224 \cdot 7^{a}$ & $23 \cdot 14$ \\
\hline
\end{tabular}

$\mathrm{BD}$, basal diet; DSS, dextran sodium sulphate; NB, navy bean; BB, black bean; DW, dry weight.

$\mathrm{a}, \mathrm{b}, \mathrm{c}$ Mean values within a row with unlike superscript letters were significantly different $(P<0 \cdot 05)$.

group $(P<0 \cdot 05)$. Colon tissue sections of the DSS-treated mice displayed an increase in crypt distortion and, as expected, had multiple erosive lesions (indicative of increased colonic damage) compared with those of the healthy control mice (representative images for all groups are shown in Fig. 2). Furthermore, the distribution of histological damage induced by DSS was similar in the proximal colon, mid-colon and distal colon (Fig. S2, available online). Both the NB + DSS and $\mathrm{BB}+$ DSS groups exhibited an increase in the total colon histological score compared with the BD + DSS group, indicating an aggravation of DSS-induced colonic damage (Fig. 2). Although the histological damage score was highest for the proximal colon and mid-colon sections of the bean diet-fed mice, a significant difference was observed only in the scores for the mid-colon section, wherein the NB diet-fed mice had significantly higher histological damage scores compared with the DSS control mice (Fig. S2, available online).

Distal colon GPx activity was increased in all the DSSexposed groups compared with that in the healthy control mice, but it did not differ between the dietary groups, indicating that DSS-induced oxidative stress in the distal colon was not modulated by the bean diets (Fig. 2). Similarly, the distal colon MPO level (indicative of neutrophil infiltration) was increased in all the DSS-treated mice compared with that in the healthy control mice; however, it did not differ between the dietary groups (Fig. 2). Additionally, a significant positive correlation existed between histological scores and colon weight:length ratio $(r$ 0.5313; $P=0.0192)$ and colonic MPO levels ( $r 0.6242 ; P=0.0033)$, confirming that these biomarkers are reflective of increased colonic inflammation and damage.

\section{Colonic mRNA expression}

All gene expression data were normalised to the expression levels in the healthy control mice (BD alone). As expected, DSS exposure led to the differential expression of $55 \%$ of the genes assessed within the Mouse Inflammatory Response and Autoimmunity PCR Array pathway compared with the gene expression in the healthy control mice (BD $v$. BD + DSS; Table S4, available online). The magnitude of the change in gene expression between the dietary groups exposed to DSS is summarised in Table 4. Compared with the BD + DSS dietary treatment, both bean diets reduced the colonic mRNA expression of the inflammatory cytokines $I L-6, I F N-\gamma$ and $I L-22 \quad(P<0.05)$ and up-regulated the expression of the anti-inflammatory cytokine $I L-10(P=0 \cdot 01)$. Additionally, both bean diets differentially affected the mucosal expression of genes involved in neutrophil chemotaxis by decreasing the expression of chemokine ( $\mathrm{C}-\mathrm{X}-\mathrm{C}$ motif) ligand 1 (Cxcl1) and $\mathrm{Cxcl5}(P=0.008$ and $P=0.037$, respectively) and increasing the expression of $I L-8 \quad(P=0.04)$. The mucosal mRNA expression of Toll-like receptor 4 (Tlr4) was modestly increased $(P=0 \cdot 003)$ and the mRNA expression of Fas ligand (FasL) was also up-regulated by both bean diets $(P=0 \cdot 001)$. Only the $\mathrm{BB}$ diet reduced the colonic mRNA expression of $I L-17 A$ compared with the BD + DSS dietary treatment $(P=0 \cdot 042)$. Conversely, only the NB diet increased the mRNA expression of chemokine ( $\mathrm{C}-\mathrm{C}$ motif) ligand (Ccl12) and CCAAT/enhancer binding protein (C/EBP), $\beta(C e b p b)(P=0.033$ and $P=0.041$, respectively) and decreased the expression of $I L-9(P=0 \cdot 047)$ compared with the BD + DSS dietary treatment.

\section{Colonic cleaved caspase-3 expression}

The level of apoptosis in the colonic epithelium of the DSS-exposed mice was determined by cleaved caspase-3 immunostaining of sections from colon Swiss rolls. As shown in Fig. 3, colon tissue sections of the NB diet-fed and $\mathrm{BB}$ diet-fed DSS-exposed mice exhibited an increase in the number of apoptotic cells within crypts throughout the entire length of the colon, compared with those of the BDfed DSS-exposed mice $(P<0 \cdot 05)$. When the colon was divided into either the proximal or the mid-distal half, it was evident that apoptosis was increased in crypts from both locations of the colon in the NB diet-fed mice, compared with that in the BD-fed DSS-exposed group $(P<0.05)$. While this pattern was similar for the BB diet-fed mice, apoptosis was significantly higher only in the proximal colon of the BB diet-fed mice, compared with that in the BD-fed DSS-exposed mice (Fig. 3). Cleaved caspase-3 immunostaining was also assessed within ulcerated areas in the colon tissue sections; however, there was no significant difference in the mean number of apoptotic cells $/ \mathrm{mm}$ ulcer between the BD-fed (16.09 (sem 3.54)), NB diet-fed (30.66 (sem 4.76)) and BB diet-fed (24.07 (sem 3.65)) DSS-exposed groups $(P>0 \cdot 05)$.

\section{Systemic response to dextran sodium sulphate exposure}

DSS exposure increased the serum concentrations of all cytokines assessed compared with those of the healthy control 


\begin{tabular}{|l|c|c|c|c|c|c|c|c|}
\hline \multirow{2}{*}{} & \multicolumn{2}{|c|}{$\begin{array}{c}\text { Colon size } \\
(\mathrm{mg} / \mathrm{mm})\end{array}$} & \multicolumn{2}{c|}{$\begin{array}{c}\text { Histological } \\
\text { score }\end{array}$} & \multicolumn{2}{c|}{ MPO (ng/mg) } & \multicolumn{2}{c|}{$\begin{array}{c}\text { GPx activity } \\
\text { (units/mg protein) }\end{array}$} \\
\cline { 2 - 9 } & Mean & SEM & Mean & SEM & Mean & SEM & Mean & SEM \\
\hline BD & $1 \cdot 5^{\mathrm{c}}$ & $0 \cdot 1$ & 0.0 & 0.0 & $158 \cdot 2^{\mathrm{b}}$ & $18 \cdot 46$ & $474^{\mathrm{b}}$ & 39 \\
BD+DSS & $2 \cdot 4^{\mathrm{b}}$ & 0.07 & $294 \cdot 5^{\mathrm{b}}$ & $10 \cdot 5$ & $2541^{\mathrm{a}}$ & $389 \cdot 9$ & $791^{\mathrm{a}}$ & 96 \\
NB+DSS & $3.0^{\mathrm{a}}$ & $0 \cdot 1$ & $406 \cdot 6^{\mathrm{a}}$ & 20.9 & $6492^{\mathrm{a}}$ & 2357 & $802^{\mathrm{a}}$ & 111 \\
BB+DSS & $2 \cdot 9^{\mathrm{a}}$ & 0.08 & $395 \cdot 1^{\mathrm{a}}$ & $20 \cdot 8$ & $4525^{\mathrm{a}}$ & 1070 & $716^{\mathrm{a}}$ & 61 \\
\hline
\end{tabular}
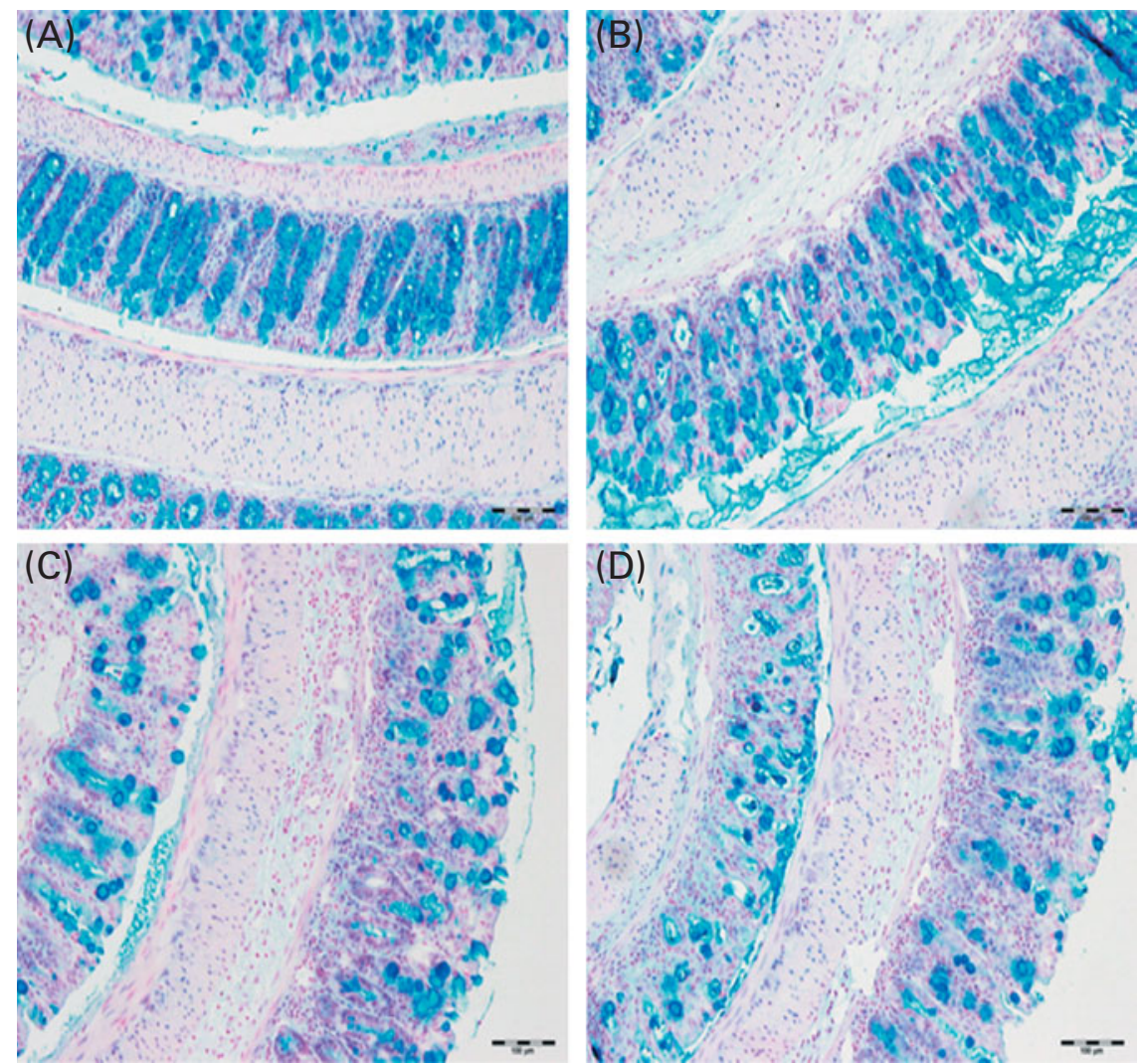

Fig. 2. Colitis severity as indicated by colon size, histological damage, myeloperoxidase (MPO) level and antioxidant (glutathione peroxidase, GPx) activity in healthy mice fed the basal diet (BD) and dextran sodium sulphate (DSS)-induced colitic mice fed the BD, navy bean (NB) diet and black bean (BB) diet. Colon size ( $n$ 12-13 per dietary group) expressed as colon weight $(\mathrm{mg}) /$ colon length $(\mathrm{mm})$. Histological scores reflect both the degree of damage and the percentage of area damaged in the entire length of the colon ( $n 7$ per dietary group). MPO levels and GPx activity $(n 10-12$ per dietary group). Values are means with their standard errors. ${ }^{\mathrm{a}, \mathrm{b}, \mathrm{c}}$ Mean values within a column with unlike superscript letters were significantly different for each analysis $(P<0.05)$. Representative colon images of tissue sections of the (A) BD, (B) BD + DSS, (C) NB + DSS and (D) BB + DSS groups stained with Alcian blue/Nuclear Fast Red (200x; scale bar 100 $\mu \mathrm{m}$ ).

mice (Fig. 4; $P<0.05$ ). In the DSS-treated mice, the serum concentrations of the inflammatory cytokines IL-1 $\beta$, IFN- $\gamma$, TNF $\alpha$ and IL-17A were reduced by both the NB and BB diets (Fig. 4(A) -(D); $P<0.05$ ), whereas the circulating concentrations of IL-6 and IL-10 did not differ between the dietary groups ( $P>0.05$; Fig. 4(E) and (F)). Additionally, serum ORAC in the BD + DSS group was significantly lower than that in the healthy control mice, indicating a decrease in antioxidant capacity following DSS exposure, which was attenuated by both bean diets (Fig. 5). Similarly, splenic tissue weights were increased in response to DSS exposure (BD + DSS $v$. BD alone), which was attenuated in both the $\mathrm{NB}+$ DSS and BB + DSS groups (Fig. 5)

\section{Discussion}

The present study assessed the effect of diets supplemented with $20 \%$ cooked common bean flours (navy and black bean varieties) on the DSS-induced acute colitis phenotype. It was hypothesised that bean diets would beneficially modulate colonic inflammation in response to DSS due to the fermentable fibre components (i.e. resistant starch, oligosaccharides and non-starch polysaccharides $)^{(19,20)}$ and phenolic compound content of beans ${ }^{(21)}$, which are known to reduce colonic inflammation and improve colon health ${ }^{(38-41,75,79,80)}$. Common beans have been investigated previously for their role as modulators of gut health, primarily in reducing colon cancer risk $^{(9,13,14,17,20,94)}$; however, the present study is the 
Table 4. Dextran sodium sulphate (DSS)-induced fold changes in proximal colon mRNA expression*

(Mean values with their standard errors)

\begin{tabular}{|c|c|c|c|c|c|c|c|}
\hline \multirow[b]{2}{*}{ Genes } & \multicolumn{2}{|c|}{$\mathrm{BD}+\mathrm{DSS}$} & \multicolumn{2}{|c|}{$N B+D S S$} & \multicolumn{2}{|c|}{$\mathrm{BB}+\mathrm{DSS}$} & \multirow[b]{2}{*}{$P$} \\
\hline & Mean & SEM & Mean & SEM & Mean & SEM & \\
\hline Col12 & $5 \cdot 7^{\mathrm{a}}$ & 1.0 & $14 \cdot 5^{\mathrm{b}}$ & 4.5 & $5 \cdot 5^{\mathrm{a}}$ & 1.4 & 0.033 \\
\hline Cxcl1 & $19 \cdot 6^{a}$ & 5.7 & $5 \cdot 7^{b}$ & 1.5 & $3.8^{\mathrm{b}}$ & 0.7 & 0.008 \\
\hline Cxcl5 & $75.0^{\mathrm{a}}$ & $15 \cdot 6$ & $19 \cdot 2^{b}$ & $5 \cdot 6$ & $10 \cdot 5^{b}$ & $2 \cdot 3$ & 0.037 \\
\hline Cebpb & $1.0^{\mathrm{a}}$ & 0.07 & $3 \cdot 2^{b}$ & 0.9 & $2 \cdot 2^{\mathrm{a}, \mathrm{b}}$ & 0.7 & 0.041 \\
\hline FasL & $0.7^{\mathrm{a}}$ & 0.2 & $2 \cdot 3^{b}$ & 0.3 & $1 \cdot 6^{\mathrm{b}}$ & 0.4 & 0.001 \\
\hline$I L-10$ & $1.7^{\mathrm{a}}$ & 0.4 & $5 \cdot 6^{\mathrm{b}}$ & 1.3 & $6.0^{\mathrm{b}}$ & $3 \cdot 1$ & 0.038 \\
\hline IFN- $\gamma$ & $6 \cdot 1^{a}$ & $2 \cdot 6$ & $2 \cdot 7^{\mathrm{b}}$ & $1 \cdot 0$ & $2 \cdot 3^{\mathrm{b}}$ & 0.6 & 0.032 \\
\hline IL-22 & $88 \cdot 6^{a}$ & $9 \cdot 4$ & $49 \cdot 1^{\mathrm{b}}$ & $10 \cdot 6$ & $29 \cdot 7^{\mathrm{b}}$ & $2 \cdot 2$ & 0.036 \\
\hline IL-6 & $396 \cdot 6^{a}$ & $56 \cdot 8$ & $79 \cdot 8^{b}$ & $18 \cdot 7$ & $56 \cdot 4^{b}$ & 10.5 & 0.003 \\
\hline IL-8 & $0.9^{a}$ & 0.2 & $3.0^{\mathrm{b}}$ & 0.2 & $3.0^{\mathrm{b}}$ & 0.8 & 0.044 \\
\hline IL-9 & $3 \cdot 2^{\mathrm{a}}$ & 0.7 & $1.5^{\mathrm{b}}$ & 0.5 & $1 \cdot 8^{\mathrm{a}, \mathrm{b}}$ & 0.5 & 0.047 \\
\hline$I L-17 A$ & $7 \cdot 4^{a}$ & 1.4 & $4 \cdot 4^{\mathrm{a}, \mathrm{b}}$ & 2.4 & $1 \cdot 3^{\mathrm{b}}$ & 0.2 & 0.042 \\
\hline TIr4 & $0.4^{\mathrm{a}}$ & 0.08 & $1.0^{\mathrm{b}}$ & 0.08 & $1.0^{\mathrm{b}}$ & 0.2 & 0.003 \\
\hline
\end{tabular}

$\mathrm{BD}$, basal diet, NB, navy bean; BB, black bean; $\mathrm{Ccl}$, chemokine ( $\mathrm{C}-\mathrm{C}$ motif) ligand; $\mathrm{CxCl}$, chemokine (C-X-C motif) ligand; Cebpb, CCAAT/enhancer binding protein (C/EBP), $\beta$; FasL, Fas ligand; IFN- $\gamma$, interferon- $\gamma$; TIr, Toll-like receptor.

${ }^{a, b}$ Mean values within a row with unlike superscript letters were significantly different $(P<0.05)$.

* Values reported are fold changes in the colonic mRNA expression of the DSStreated mice ( $n$ 6-7 per dietary group) normalised to the expression level of the BD-fed healthy control mice ( $n 4)$. The effect of diet on DSS-induced changes in mRNA expression for each gene detected on the Mouse Inflammatory Response and Autoimmunity PCR Arrays (PAMM-077Z; Qiagen) was analysed by one-way ANOVA, and only the results obtained for genes that were differentially expressed between the dietary groups in response to DSS are reported.

first to demonstrate their role in the modulation of colitis and colitis-associated systemic inflammation.

In the present study, critical mediators of colonic and systemic inflammation and colonic mucosal damage were clearly modulated by the bean diets in mice exposed to DSS. Evidence of a reduced local (colonic) inflammatory response to DSS in the bean diet-fed groups was supported by the reduced mRNA expression of the pro-inflammatory cytokines $I L-6$ and $I F N-\gamma$ and the up-regulated mRNA expression of the anti-inflammatory cytokine $I L-10$ (Table 4). The bean-associated anti-inflammatory phenotype was extended systemically, as circulating concentrations of the inflammatory cytokines IL- $1 \beta$, IFN- $\gamma$, TNF- $\alpha$ and IL-17A were reduced (Fig. 4), serum antioxidant capacity was preserved and spleen hypertrophy was attenuated (Fig. 5) in the NB and BB dietary groups. This effect could be interpreted to reflect a reduced magnitude in the inflammatory response generated following exposure to DSS, as circulating cytokine concentrations represent a spillover into the extravascular compartment wherein inflammatory responses are generated ${ }^{(95)}$. On the other hand, the bean diets enhanced DSS-induced colon histological damage (Fig. 2) and increased the mRNA expression of FasL (apoptosis mediator) (Table 4) and the number of apoptotic cells in the colon (Fig. 3), indicating the aggravation of DSS-induced colitis. Overall, the present results demonstrate that bean diets beneficially modulate some biomarkers of colonic and systemic inflammation while simultaneously enhancing DSS-induced colonic damage and apoptosis.

The beneficial effects observed following the consumption of bean diets may have been driven by the SCFA, in particular, butyrate - a microbial fermentation end product of non-digestible bean components ${ }^{(11,12)}$. Mechanistically, butyrate is an important energy source for the maintenance

(A)

\begin{tabular}{|l|l|l|l|l|l|l|}
\hline & \multicolumn{2}{|c|}{ Entire colon } & \multicolumn{2}{c|}{$\begin{array}{c}\text { Proximal } \\
\text { colon }\end{array}$} & \multicolumn{2}{c|}{$\begin{array}{c}\text { Mid and distal } \\
\text { colon }\end{array}$} \\
\hline Group & Mean & SEM & Mean & SEM & Mean & SEM \\
\hline BD+DSS & $14 \cdot 38^{\mathrm{b}}$ & 1.82 & $10 \cdot 86^{\mathrm{b}}$ & 1.45 & $15 \cdot 05^{\mathrm{b}}$ & $2 \cdot 73$ \\
NB+DSS & $34 \cdot 88^{\mathrm{a}}$ & 3.01 & $36 \cdot 56^{\mathrm{a}}$ & 5.94 & $37 \cdot 2^{\mathrm{a}}$ & 5.02 \\
BB+DSS & $25 \cdot 41^{\mathrm{a}}$ & 2.52 & $34 \cdot 32^{\mathrm{a}}$ & $7 \cdot 11$ & $22 \cdot 27^{\mathrm{ab}}$ & 3.44 \\
\hline
\end{tabular}

(B)

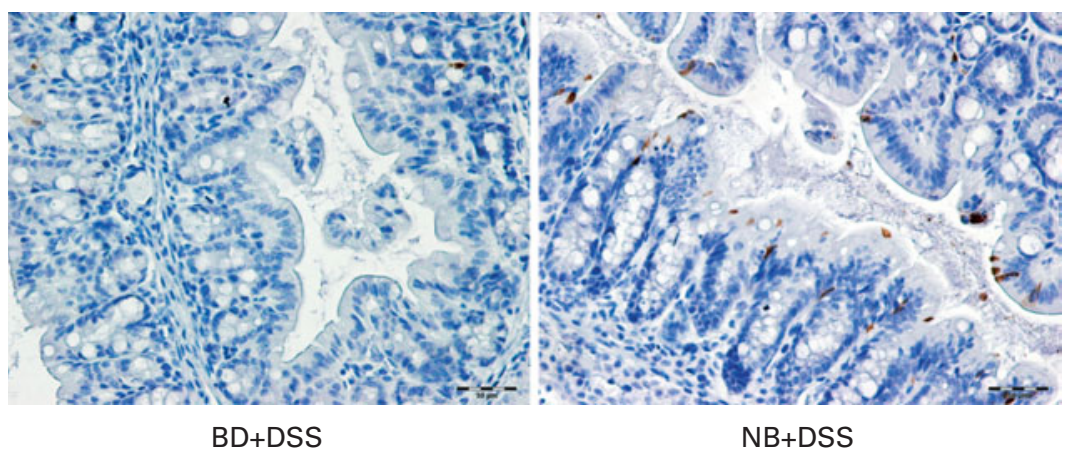

Fig. 3. Cleaved caspase-3-positive apoptotic cells in the colonic epithelium of the dextran sodium sulphate (DSS)-exposed mice. Cleaved caspase-3 expression was analysed by immunohistochemistry in the colon sections of the DSS-treated mice fed the basal diet (BD), navy bean (NB) diet or black bean (BB) diet. (A) Total number of positive cells/mm colon within crypt-containing areas along the entire colon, proximal colon, and mid and distal colon. Values are means with their standard errors. ${ }^{a, b}$ Mean values within a column with unlike superscript letters were significantly different $(P<0.05$; Kruskal-Wallis followed by Dunn's multiple comparison test). (B) Representative images of the proximal colon of the DSS-exposed BD-fed, NB diet-fed and BB diet-fed mice, wherein brown-stained cells demonstrate cleaved caspase-3 immunostaining (500x; scale bar $50 \mu \mathrm{m})$. 

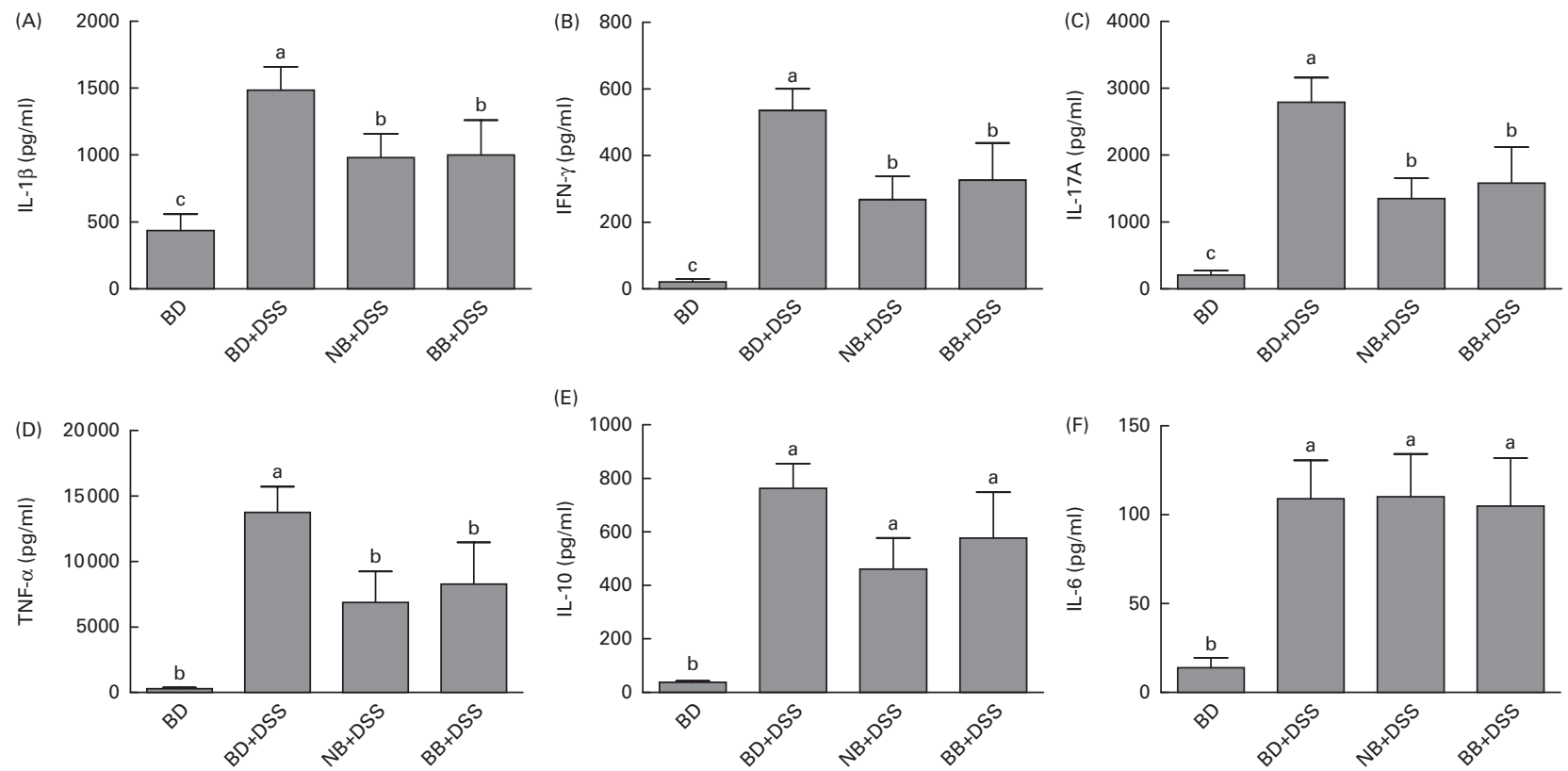

Fig. 4. Serum cytokine concentrations of (A) IL-1 $\beta$, (B) interferon- $\gamma$ (IFN- $\gamma$ ), (C) IL-17A (D) TNF- $\alpha$, (E) IL-10 and (F) IL-6 in healthy mice fed the basal diet (BD) and dextran sodium sulphate (DSS)-induced colitic mice fed the BD, navy bean (NB) diet and black bean (BB) diet. Values are means, with their standard errors represented by vertical bars. ${ }^{\mathrm{a}, \mathrm{b}, \mathrm{c}}$ Mean values with unlike superscript letters were significantly different $(P<0.05)$.

and growth of colonocytes, enhancing the integrity of the gut barrier and exerting direct effects within the colon epithelium through the modulation of inflammation-related signalling pathways, in part, through the inhibition of histone deacetylase activity ${ }^{(22-24)}$. In the present study, the caecal concentrations of SCFA (acetate, propionate and butyrate) were increased by the bean diets (Table 3). Furthermore, proximal colon samples of the bean diet-fed mice exhibited reduced mRNA expression of IFN- $\gamma, I L-6$, and $C x C l 5$, as well as increased expression of $I L-10$ (Table 4), pro- and anti-inflammatory mediators previously been shown to be modulated by butyrate ${ }^{(96-98)}$. Interestingly, although the bean diets reduced the proximal colon mRNA expression of the chemokines Cxcl1 and Cxcl5, which are involved in the recruitment of immune cells to the inflamed colon ${ }^{(99)}$, distal colon MPO levels (biomarker of neutrophil infiltration) did not differ significantly between the DSS-exposed groups (Fig. 2). Generally, SCFA are more concentrated in the proximal colon and gradually deplete as the faeces moves through the colon $^{(100)}$. Therefore, if the bean-induced changes in chemokine mRNA expression in the proximal colon were mediated by butyrate, this effect may not have persisted in the distal regions of the colon, where butyrate concentrations are low.

Beans are also a rich source of phenolic compounds ${ }^{(21,85,86)}$, and it was hypothesised that higher phenolic content and antioxidant activity may result in lower oxidative stress and, therefore, an attenuation of colitis symptoms. Both IBD and DSS-induced animal models of colitis are associated with increased colonic and systemic biomarkers of oxidative stress $^{(55-58,101,102)}$. Oxidative stress results from the increased production of reactive oxygen species and reactive nitrogen species, produced mainly by activated inflammatory cells,
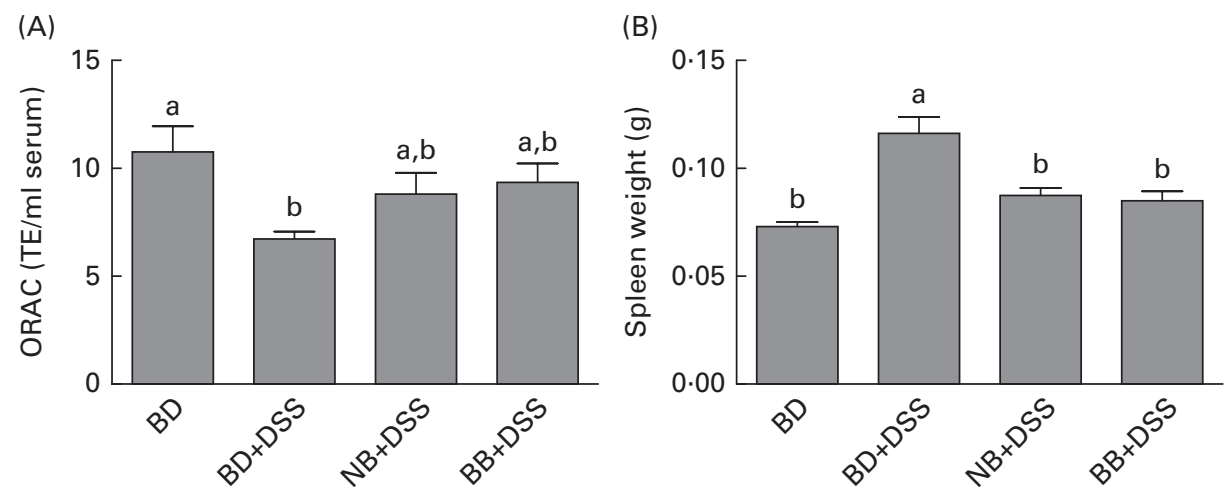

Fig. 5. Systemic effects of the bean diets on spleen weight and serum antioxidant status in healthy mice fed the basal diet (BD) and dextran sodium sulphate (DSS)-induced colitic mice fed the BD, navy bean (NB) diet and black bean (BB) diet. (A) Serum antioxidant capacity measured by oxygen radical absorbance capacity (ORAC, $n$ 5-6 per dietary group). (B) Spleen weight ( $n$ 11-13 per dietary group). Values are means, with their standard errors represented by vertical bars. ${ }^{a, b}$ Mean values with unlike superscript letters were significantly different $(P<0.05)$. TE, Trolox equivalents. 
which aggravate colonic damage and perpetuate the inflammatory cycle ${ }^{(102,103)}$. Therefore, antioxidants are currently being investigated for their role in the reduction of oxidative stress in colitis ${ }^{(37,104-106)}$. Both bean diets contained higher phenolic compound content (increased total phenolic content and total flavonoid content) and antioxidant potential (increased FRAP and ORAC) compared with the BD (Table 2). In both instances, the $\mathrm{BB}$ diet had the highest phenolic compound load and antioxidant activity, which could be attributed to the addition of anthocyanins that were present only in the BB diet (Fig. S1, available online). Moreover, faecal phenolic compound content and antioxidant activity were elevated in mice that consumed both the beancontaining diets compared with those in mice that consumed the BD (Table 2), with the highest levels being detected in samples obtained from mice that consumed the $\mathrm{BB}$ diet, thereby demonstrating that these compounds were reaching the distal colon and could exert direct effects during colitis.

Mechanistically, however, the role of bean phenolics as antioxidants in the colon tissue was not supported in the present study. DSS is known to increase oxidative stress in the colon tissue, thereby increasing tissue antioxidant enzyme activity (i.e. GPx) ${ }^{(107,108)}$. The present study supports previous findings, demonstrating that DSS exposure increases colonic GPx activity and MPO levels (enzyme involved in free-radical generation) ${ }^{(102)}$ in the colon tissue (Fig. 2). Similarly, serum ORAC, a measure of systemic antioxidant capacity, was reduced in DSS-exposed mice fed the BD (Fig. 5), indicating the depletion of endogenous antioxidants potentially due to elevated oxidative stress ${ }^{(101,109)}$. However, colonic GPx activity in the bean diet-fed groups did not differ from that in the DSS control mice, indicating that the bean phenolics were not acting as antioxidants in the colon tissue. On the other hand, the bean diet-fed DSS-exposed mice had serum ORAC that did not differ from that of the healthy control mice, indicating improved or sustained systemic antioxidant capacity (Fig. 5). Whether this indicates an increase in circulating antioxidants due to phenolicrich bean consumption or a general reduction in systemic inflammation, and thus oxidative stress, in the bean diet-fed mice is currently unknown. However, the reduction of serum cytokine concentrations (Fig. 4) and attenuation of spleen hypertrophy (Fig. 5) induced by the bean diets indicate an overall reduction of systemic inflammation.

Phenolic compounds are also known to induce a myriad of cellular effects, beyond that of their antioxidant potential. One mechanism through which bean phenolic compounds exert an anti-inflammatory effect is the modulation of NF- $\mathrm{kB}$ signalling and subsequent expression of inflammatory mediators such as IL-6, TNF- $\alpha$ and IL-1 $\beta^{(38-41,110-117)}$. Interestingly, despite the $\mathrm{BB}$ diet having a higher phenolic content, both the NB and $\mathrm{BB}$ diets exhibited similar effects on inflammatory cytokine expression by reducing the colonic mRNA levels of IL-6 (Table 4) and the circulating concentrations of both TNF- $\alpha$ and IL-1 $\beta$ (Fig. 4). However, compared with the $\mathrm{BD}+\mathrm{DSS}$ dietary treatment, only the $\mathrm{BB}$ diet reduced the colonic mRNA expression of $I L-17 A$, indicating an additional anti-inflammatory benefit that could be attributed to the presence of anthocyanins, which have been shown to reduce colitis severity $^{(118,119)}$. Collectively, our data demonstrate that bean phenolic compounds may account, at least in part, for the observed reduction of pro-inflammatory cytokine concentrations, which contributes to the decrease in the severity of the colitis phenotype.

On the other hand, the bean diets also induced a significant increase in the colonic architectural damage caused by DSS (Fig. 2). While the mechanisms by which beans mediated this response are not yet clear, both bean diets up-regulated the proximal colon mRNA expression of FasL compared with that in the DSS control group (Table 4). FasL targets cells to undergo apoptosis via the trimerisation of the Fas receptor and subsequent recruitment of caspase 8, which in turn activates caspase-3, leading to apoptosis ${ }^{(120)}$. We also demonstrated an increase in the number of apoptotic (cleaved caspase-3) cells within the colon crypts of the bean diet-fed mice compared with that in the DSS control group (Fig. 3). An increase in apoptosis can result in reduced gut barrier integrity, impaired wound healing and delayed epithelial restitution, which would lead to increased or prolonged damage caused by $\operatorname{DSS}^{(121-124)}$. Thus, increased apoptosis may have played a role in the bean diet-mediated increase in colonic damage observed in the present study.

Currently, there is no evidence to suggest that cooked bean-supplemented diets would induce toxic or adverse effects in the colon. Although raw beans are known to contain a number of anti-nutritional components (i.e. lectins and protease inhibitors) that may adversely affect gut health, the method used for preparing the cooked bean flours (i.e. soaking and heating) in the present study might have reduced their content in the animal diets ${ }^{(8,125,126)}$. Furthermore, many animal studies of longer duration and higher doses of cooked beans have been conducted with no reports of adverse health effects, reduced dietary intake or growth rate ${ }^{(17,127-129)}$. The present results also confirm that the bean diets were well tolerated by the mice, as the growth rate and diet intake did not differ between the dietary groups (Table S3, available online). This may suggest that this phenomenon was related to the disease model and/or the colitis induction system employed in the present study, in particular, the use of DSS to induce colitis.

Increased colonic damage may be caused by increased DSS exposure; however, we did not observe differences in water intake during DSS exposure (Fig. 1), indicating that the intake of DSS did not differ between the dietary groups. On the other hand, there may have been differences in the delivery of DSS to the colon. In fact, earlier studies have reported that the consumption of bean-supplemented diets increases gastrointestinal transit time in rodents ${ }^{(130)}$. Therefore, the increased gastrointestinal transit time might have prolonged the exposure of the luminal contents to the intestinal tract, including DSS, thereby inducing greater mucosal damage in the bean diet-fed mice. Although the diets used in the present study contained equal macronutrient and total dietary fibre levels (Table 1), the bean diets contained an array of non-digestible fermentable components, which may have 
increased intestinal lumen viscosity, water-holding capacity of the digesta and intestinal transit time ${ }^{(131)}$. This potential caveat in the study of complex food matrixes in the DSS-induced colitis model requires further investigation, which we are currently exploring. Future studies assessing the dose and timing of bean consumption relative to colitis onset may be useful for determining the balance between the beneficial and adverse effects elicited by the bean diets in relation to the severity of the colitis phenotype. For example, the antiinflammatory effects of beans may reduce the severity of colon inflammation upon initiation, but continued consumption during colitis relapse may ultimately aggravate disease symptoms.

In summary, dietary incorporation of whole cooked beans improved the DSS-induced colitis phenotype by reducing inflammatory mediator expression both locally within the inflamed colon and systemically, an effect attributable to the bean bioactive components, namely fermentation-derived SCFA and/or phenolic compounds. The amount of evidence supporting an anti-inflammatory role of diet-derived bioactives and extracts is increasing ${ }^{(132,133)}$; however, there is a lack of information regarding the impact of consuming whole foods. In the present study, whole beans were cooked in the same manner as commonly prepared domestically, thereby providing an additional advantage when translating the outcomes to the clinical setting. However, in the present study, to incorporate cooked beans into the experimental diets, a freeze-drying step was utilised. Freezedrying is known to alter the physical characteristics of starch, leading to a potential increase in retrograded (i.e. resistant) starch content in the experimental bean diets and production of $\mathrm{SCFA}^{(11,134)}$, thereby producing a potential limitation in translating the present results to those expected from consuming domestically processed beans. Furthermore, the bean supplementation level used in the present study (20\%) may be achievable for human consumption ${ }^{(135)}$; however, future dose-response studies are required to determine the potential health benefits of lower bean supplementation levels. In clinical practice, a combination of intervention strategies designed to reduce the inflammatory response, control IBD symptoms and prolong remission is commonly employed ${ }^{(66)}$. Dietary intervention represents an additional component that may be effective in combination with pharmaceuticals at reducing disease severity, and in this context, increased consumption of beans may prove beneficial. On the other hand, the bean-supplemented diets led to an increase in DSS-induced mucosal damage, an effect which we hypothesise to be caused by an interaction between the bean diets and the DSS. Therefore, a potential limitation may exist in the use of this colitis model when examining the role of complex food matrices in colonic inflammation; however, this hypothesis requires further study.

\section{Supplementary material}

To view supplementary material for this article, please visit http://dx.doi.org/10.1017/S0007114513004352

\section{Acknowledgements}

The present study was funded by the Ontario Ministry of Agriculture and Food, Ontario Research Fund (RE-04-043) and Agriculture and Agri-Food Canada.

The authors' contributions are as follows: K. A. P., R. T. and K. P. P. selected the bean varieties; C. Z. and K. A. P. designed the study; C. Z., J. T. L., L. Z., W. W. and K. A. P. conducted the animal trial; C. Z., R. T. and R. L. conducted the chemical analyses; C. Z., J. M. M., W. W. and K. A. P. carried out all the other analyses; G. A. W. and L. R. provided consultation and expertise for the histological and cytokine analyses; C. Z., J. M. M. and K. A. P. conducted the statistical analyses, interpreted the data and wrote the manuscript. All authors read and approved the final manuscript.

The authors declare no conflicts of interest.

\section{References}

1. Bischoff SC (2011) 'Gut health': a new objective in medicine? BMC Med 9, 24

2. Cerf-Bensussan N \& Gaboriau-Routhiau V (2010) The immune system and the gut microbiota: friends or foes? Nat Rev Immunol 10, 735-744.

3. Zhu Y, Michelle Luo T, Jobin C, et al. (2011) Gut microbiota and probiotics in colon tumorigenesis. Cancer Lett 309, 119-127.

4. Sanz Y, Santacruz A \& Gauffin P (2010) Gut microbiota in obesity and metabolic disorders. Proc Nutr Soc 69, 434-441.

5. Harris K, Kassis A, Major G, et al. (2012) Is the gut microbiota a new factor contributing to obesity and its metabolic disorders? J Obes 2012, 879151.

6. Kelly D \& Mulder IE (2012) Microbiome and immunological interactions. Nutr Rev 70, Suppl. 1, S18-S30.

7. Dilis V \& Trichopoulou A (2009) Nutritional and health properties of pulses. Mediterr J Nutr Metab 1, 149-157.

8. Gebrelibanos M, Tesfaye D, Raghavendra Y, et al. (2013) Nutritional and health implications of legumes. Int $J$ Pharm Sci Res 4, 1269-1279.

9. Mathers JC (2002) Pulses and carcinogenesis: potential for the prevention of colon, breast and other cancers. $\mathrm{Br} J$ Nutr 88, Suppl. 3, S273-S279.

10. Finley JW, Burrell JB \& Reeves PG (2007) Pinto bean consumption changes SCFA profiles in fecal fermentations, bacterial populations of the lower bowel, and lipid profiles in blood of humans. $J$ Nutr 137, 2391-2398.

11. Henningsson AM, Nyman EM \& Bjorck IM (2001) Content of short-chain fatty acids in the hindgut of rats fed processed bean (Phaseolus vulgaris) flours varying in distribution and content of indigestible carbohydrates. Br J Nutr 86, 379-389.

12. Hernandez-Salazar M, Osorio-Diaz P, Loarca-Pina G, et al. (2010) In vitro fermentability and antioxidant capacity of the indigestible fraction of cooked black beans (Phaseolus vulgaris L.), lentils (Lens culinaris L.) and chickpeas (Cicer arietinum L.). J Sci Food Agric 90, 1417-1422.

13. Vergara-Castaneda HA, Guevara-Gonzalez RG, RamosGomez M, et al. (2010) Non-digestible fraction of cooked bean (Phaseolus vulgaris L.) cultivar Bayo Madero suppresses colonic aberrant crypt foci in azoxymethaneinduced rats. Food Funct 1, 294-300.

14. Hayde VC, Ramon GG, Lorenzo GO, et al. (2012) Non-digestible fraction of beans (Phaseolus vulgaris L.) 
modulates signalling pathway genes at an early stage of colon cancer in Sprague-Dawley rats. Br J Nutr $\mathbf{1 0 8}$, Suppl. 1, S145-S154.

15. Correa P (1981) Epidemiological correlations between diet and cancer frequency. Cancer Res 41, 3685-3690.

16. Lanza E, Hartman TJ, Albert PS, et al. (2006) High dry bean intake and reduced risk of advanced colorectal adenoma recurrence among participants in the polyp prevention trial. J Nutr 136, 1896-1903.

17. Bobe G, Barrett KG, Mentor-Marcel RA, et al. (2008) Dietary cooked navy beans and their fractions attenuate colon carcinogenesis in azoxymethane-induced $o b / o b$ mice. Nutr Cancer 60, 373-381.

18. Bobe G, Sansbury LB, Albert PS, et al. (2008) Dietary flavonoids and colorectal adenoma recurrence in the Polyp Prevention Trial. Cancer Epidemiol Biomarkers Prev 17, 1344-1353.

19. Campos-Vega R, Reynoso-Camacho R, Pedraza-Aboytes G, et al. (2009) Chemical composition and in vitro polysaccharide fermentation of different beans (Phaseolus vulgaris L.). J Food Sci 74, T59-T65.

20. Cruz-Bravo RK, Guevara-Gonzalez R, Ramos-Gomez M, et al. (2011) Fermented nondigestible fraction from common bean (Phaseolus vulgaris L.) cultivar Negro 8025 modulates HT-29 cell behavior. J Food Sci 76, T41-T47.

21. Lin L-Z, Harnly JM, Pastor-Corrales MS, et al. (2008) The polyphenolic profiles of common bean (Phaseolus vulgaris L.). Food Chem 107, 399-410.

22. Leonel AJ \& Alvarez-Leite JI (2012) Butyrate: implications for intestinal function. Curr Opin Clin Nutr Metab Care 15, 474-479.

23. Hamer HM, Jonkers D, Venema K, et al. (2008) Review article: the role of butyrate on colonic function. Aliment Pharmacol Ther 27, 104-119.

24. Roediger WE (1980) Role of anaerobic bacteria in the metabolic welfare of the colonic mucosa in man. Gut $\mathbf{2 1}$ 793-798.

25. Langlands SJ, Hopkins MJ, Coleman N, et al. (2004) Prebiotic carbohydrates modify the mucosa associated microflora of the human large bowel. Gut 53, 1610-1616.

26. Kim YS \& Milner JA (2007) Dietary modulation of colon cancer risk. J Nutr 137, 2576S-2579S.

27. Butzner JD, Parmar R, Bell CJ, et al. (1996) Butyrate enema therapy stimulates mucosal repair in experimental colitis in the rat. Gut 38, 568-573.

28. Di Sabatino A, Morera R, Ciccocioppo R, et al. (2005) Oral butyrate for mildly to moderately active Crohn's disease. Aliment Pharmacol Ther 22, 789-794.

29. Scheppach W, Sommer H, Kirchner T, et al. (1992) Effect of butyrate enemas on the colonic mucosa in distal ulcerative colitis. Gastroenterology 103, 51-56.

30. Segain JP, Raingeard de la Bletiere D, Bourreille A, et al. (2000) Butyrate inhibits inflammatory responses through NF-kappaB inhibition: implications for Crohn's disease. Gut 47, 397-403.

31. Steinhart AH, Hiruki T, Brzezinski A, et al. (1996) Treatment of left-sided ulcerative colitis with butyrate enemas a controlled trial. Aliment Pharmacol Ther 10, 729-736.

32. Tedelind S, Westberg F, Kjerrulf M, et al. (2007) Antiinflammatory properties of the short-chain fatty acids acetate and propionate: a study with relevance to inflammatory bowel disease. World J Gastroenterol 13, 2826-2832.

33. Cardona F, Andres-Lacueva C, Tulipani S, et al. (2013) Benefits of polyphenols on gut microbiota and implications in human health. J Nutr Biochem 24, 1415-1422.
34. Guajardo-Flores D, Serna-Saldivar SO \& Gutierrez-Uribe JA (2013) Evaluation of the antioxidant and antiproliferative activities of extracted saponins and flavonols from germinated black beans (Phaseolus vulgaris L.). Food Chem 141, 1497-1503.

35. Kumazaki M, Noguchi S, Yasui Y, et al. (2013) Anti-cancer effects of naturally occurring compounds through modulation of signal transduction and miRNA expression in human colon cancer cells. J Nutr Biochem 24, 1849-1858.

36. Banerjee N, Kim H, Talcott S, et al. (2013) Pomegranate polyphenolics suppressed azoxymethane-induced colorectal aberrant crypt foci and inflammation: possible role of miR-126/VCAM-1 and miR-126/PI3K/AKT/mTOR. Carcinogenesis 34, 2814-2822.

37. Sung MK \& Park MY (2013) Nutritional modulators of ulcerative colitis: clinical efficacies and mechanistic view. World J Gastroenterol 19, 994-1004.

38. Yao J, Wang JY, Liu L, et al. (2010) Anti-oxidant effects of resveratrol on mice with DSS-induced ulcerative colitis. Arch Med Res 41, 288-294.

39. Romier B, Schneider YJ, Larondelle Y, et al. (2009) Dietary polyphenols can modulate the intestinal inflammatory response. Nutr Rev 67, 363-378.

40. Kim SJ, Kim MC, Um JY, et al. (2010) The beneficial effect of vanillic acid on ulcerative colitis. Molecules 15, 7208-7217.

41. Park MY, Ji GE \& Sung MK (2012) Dietary kaempferol suppresses inflammation of dextran sulfate sodium-induced colitis in mice. Dig Dis Sci 57, 355-363.

42. Dong WG, Liu SP, Yu BP, et al. (2003) Ameliorative effects of sodium ferulate on experimental colitis and their mechanisms in rats. World J Gastroenterol 9, 2533-2538.

43. Ulluwishewa D, Anderson RC, McNabb WC, et al. (2011) Regulation of tight junction permeability by intestinal bacteria and dietary components. J Nutr 141, 769-776.

44. Suzuki T \& Hara H (2011) Role of flavonoids in intestinal tight junction regulation. J Nutr Biochem 22, 401-408.

45. Tuohy KM, Conterno L, Gasperotti M, et al. (2012) Up-regulating the human intestinal microbiome using whole plant foods, polyphenols, and/or fiber. J Agric Food Chem 60, 8776-8782.

46. Hervert-Hernández D \& Goñi I (2011) Dietary polyphenols and human gut microbiota: a review. Food Rev Int 27, 154-169.

47. Etxeberria U, Fernandez-Quintela A, Milagro FI, et al. (2013) Impact of polyphenols and polyphenol-rich dietary sources on gut microbiota composition. J Agric Food Chem 61, 9517-9533.

48. Rubin DC, Shaker A \& Levin MS (2012) Chronic intestinal inflammation: inflammatory bowel disease and colitisassociated colon cancer. Front Immunol 3, 107.

49. Lakatos PL \& Lakatos L (2008) Risk for colorectal cancer in ulcerative colitis: changes, causes and management strategies. World J Gastroenterol 14, 3937-3947.

50. Sha S, Xu B, Wang X, et al. (2013) The biodiversity and composition of the dominant fecal microbiota in patients with inflammatory bowel disease. Diagn Microbiol Infect Dis 75, 245-251.

51. Fabia R, Ar'Rajab A, Johansson ML, et al. (1993) Impairment of bacterial flora in human ulcerative colitis and experimental colitis in the rat. Digestion 54, 248-255.

52. Takaishi H, Matsuki T, Nakazawa A, et al. (2008) Imbalance in intestinal microflora constitution could be involved in the pathogenesis of inflammatory bowel disease. Int J Med Microbiol 298, 463-472. 
53. Sasaki M \& Klapproth JM (2012) The role of bacteria in the pathogenesis of ulcerative colitis. J Signal Transduct 2012, 704953.

54. de Wouters T, Dore J \& Lepage P (2012) Does our food (environment) change our gut microbiome ('in-vironment'): a potential role for inflammatory bowel disease? Dig Dis $\mathbf{3 0}$, Suppl. 3, 33-39.

55. Lih-Brody L, Powell SR, Collier KP, et al. (1996) Increased oxidative stress and decreased antioxidant defenses in mucosa of inflammatory bowel disease. Dig Dis Sci $\mathbf{4 1}$, 2078-2086.

56. Barbosa DS, Cecchini R, El Kadri MZ, et al. (2003) Decreased oxidative stress in patients with ulcerative colitis supplemented with fish oil $\omega-3$ fatty acids. Nutrition 19, $837-842$.

57. Forrest CM, Gould SR, Darlington LG, et al. (2003) Levels of purine, kynurenine and lipid peroxidation products in patients with inflammatory bowel disease. Adv Exp Med Biol 527, 395-400.

58. Kruidenier L, Kuiper I, Lamers CB, et al. (2003) Intestinal oxidative damage in inflammatory bowel disease: semiquantification, localization, and association with mucosal antioxidants. J Pathol 201, 28-36.

59. Xavier RJ \& Podolsky DK (2007) Unravelling the pathogenesis of inflammatory bowel disease. Nature 448, 427-434.

60. Gecse K, Roka R, Sera T, et al. (2012) Leaky gut in patients with diarrhea-predominant irritable bowel syndrome and inactive ulcerative colitis. Digestion 85, 40-46.

61. Kiesslich R, Duckworth CA, Moussata D, et al. (2012) Local barrier dysfunction identified by confocal laser endomicroscopy predicts relapse in inflammatory bowel disease. Gut 61, 1146-1153.

62. Gersemann M, Wehkamp J \& Stange EF (2012) Innate immune dysfunction in inflammatory bowel disease. J Intern Med 271, 421-428.

63. McGuckin MA, Eri R, Simms LA, et al. (2009) Intestinal barrier dysfunction in inflammatory bowel diseases. Inflamm Bowel Dis 15, 100-113.

64. Atreya I, Atreya R \& Neurath MF (2008) NF-kappaB in inflammatory bowel disease. J Intern Med 263, 591-596.

65. Lennard-Jones JE, Longmore AJ, Newell AC, et al. (1960) An assessment of prednisone, salazopyrin, and topical hydrocortisone hemisuccinate used as out-patient treatment for ulcerative colitis. Gut 1, 217-222.

66. Carter MJ, Lobo AJ \& Travis SPL (2004) Guidelines for the management of inflammatory bowel disease in adults. Gut 53, V1-V16.

67. Gionchetti P, Rizzello F, Lammers KM, et al. (2006) Antibiotics and probiotics in treatment of inflammatory bowel disease. World J Gastroenterol 12, 3306-3313.

68. Dignass A, Lindsay JO, Sturm A, et al. (2012) Second European evidence-based consensus on the diagnosis and management of ulcerative colitis Part 2: current management. J Crohns Colitis 6, 991-1030.

69. Manz M, Vavricka SR, Wanner R, et al. (2012) Therapy of steroid-resistant inflammatory bowel disease. Digestion 86, Suppl. 1, 11-15.

70. Gonzalez R, Ballester I, Lopez-Posadas R, et al. (2011) Effects of flavonoids and other polyphenols on inflammation. Crit Rev Food Sci Nutr 51, 331-362.

71. Irving GR, Karmokar A, Berry DP, et al. (2011) Curcumin: the potential for efficacy in gastrointestinal diseases. Best Pract Res Clin Gastroenterol 25, 519-534.

72. Neuman MG \& Nanau RM (2012) Inflammatory bowel disease: role of diet, microbiota, life style. Transl Res $\mathbf{1 6 0}$, $29-44$.
73. Tighe MP, Cummings JR \& Afzal NA (2011) Nutrition and inflammatory bowel disease: primary or adjuvant therapy. Curr Opin Clin Nutr Metab Care 14, 491-496.

74. Vernia P, Annese V, Bresci G, et al. (2003) Topical butyrate improves efficacy of 5-ASA in refractory distal ulcerative colitis: results of a multicentre trial. Eur J Clin Invest 33, $244-248$.

75. Rodriguez-Cabezas ME, Galvez J, Lorente MD, et al. (2002) Dietary fiber down-regulates colonic tumor necrosis factor alpha and nitric oxide production in trinitrobenzenesulfonic acid-induced colitic rats. J Nutr 132, 3263-3271.

76. Vieira EL, Leonel AJ, Sad AP, et al. (2012) Oral administration of sodium butyrate attenuates inflammation and mucosal lesion in experimental acute ulcerative colitis. J Nutr Biochem 23, 430-436.

77. Nishimura T, Andoh A, Hashimoto T, et al. (2010) Cellobiose prevents the development of dextran sulfate sodium (DSS)-induced experimental colitis. J Clin Biochem Nutr 46, 105-110.

78. Koleva PT, Valcheva RS, Sun X, et al. (2012) Inulin and fructo-oligosaccharides have divergent effects on colitis and commensal microbiota in HLA-B27 transgenic rats. $\mathrm{Br}$ J Nutr 108, 1633-1643.

79. Rodriguez-Cabezas ME, Camuesco D, Arribas B, et al (2010) The combination of fructooligosaccharides and resistant starch shows prebiotic additive effects in rats. Clin Nutr 29, 832-839.

80. Moreau NM, Martin LJ, Toquet CS, et al. (2003) Restoration of the integrity of rat caeco-colonic mucosa by resistant starch, but not by fructo-oligosaccharides, in dextran sulfate sodium-induced experimental colitis. Br J Nutr 90, 75-85.

81. Andujar I, Recio MC, Giner RM, et al. (2011) Inhibition of ulcerative colitis in mice after oral administration of a polyphenol-enriched cocoa extract is mediated by the inhibition of STAT1 and STAT3 phosphorylation in colon cells. J Agric Food Chem 59, 6474-6483.

82. Larrosa M, Gonzalez-Sarrias A, Yanez-Gascon MJ, et al. (2010) Anti-inflammatory properties of a pomegranate extract and its metabolite urolithin-A in a colitis rat model and the effect of colon inflammation on phenolic metabolism. J Nutr Biochem 21, 717-725.

83. Baliga MS, Joseph N, Venkataranganna MV, et al. (2012) Curcumin, an active component of turmeric in the prevention and treatment of ulcerative colitis: preclinical and clinical observations. Food Funct 3, 1109-1117.

84. Beninger CW \& Hosfield GL (1999) Flavonoid composition of three genotypes of dry bean (Phaseolus vulgaris) differing in seed coat color. J Am Soc Hortic Sci 124, 514-518.

85. Espinosa-Alonso LG, Lygin A, Widholm JM, et al. (2006) Polyphenols in wild and weedy Mexican common beans (Phaseolus vulgaris L.). J Agric Food Chem 54, 4436-4444.

86. Ranilla LG, Genovese MI \& Lajolo FM (2007) Polyphenols and antioxidant capacity of seed coat and cotyledon from Brazilian and Peruvian bean cultivars (Phaseolus vulgaris L.). J Agric Food Chem 55, 90-98.

87. Masoodi I, Tijjani BM, Wani H, et al. (2011) Biomarkers in the management of ulcerative colitis: a brief review. Ger Med Sci 9, Doc03.

88. Charpentier C, Marion-Letellier R, Savoye G, et al. (2012) Magnetic resonance colonography in rats with TNBSinduced colitis: a feasibility and validation study. Inflamm Bowel Dis 18, 1940-1949.

89. Sugawara T \& Miyazawa T (2001) Beneficial effect of dietary wheat glycolipids on cecum short-chain fatty acid and secondary bile acid profiles in mice. J Nutr Sci Vitaminol (Tokyo) 47, 299-305. 
90. Sutivisedsak N, Cheng HN, Willett JL, et al. (2010) Microwave-assisted extraction of phenolics from bean (Phaseolus vulgaris L.). Food Res Int 43, 516-519.

91. Espín JC, González-Barrio R, Cerdá B, et al. (2007) Iberian pig as a model to clarify obscure points in the bioavailability and metabolism of ellagitannins in humans. J Agric Food Chem 55, 10476-10485.

92. Li H, Deng Z, Liu R, et al. (2011) Characterization of phytochemicals and antioxidant activities of a purple tomato (Solanum lycopersicum L.). J Agric Food Chem 59, 11803-11811.

93. Zhishen J, Mengcheng T \& Jianming W (1999) The determination of flavonoid contents in mulberry and their scavenging effects on superoxide radicals. Food Chem 64, $555-559$.

94. Campos-Vega R, García-Gasca T, Guevara-Gonzalez R, et al. (2012) Human gut flora-fermented nondigestible fraction from cooked bean (Phaseolus vulgaris L.) modifies protein expression associated with apoptosis, cell cycle arrest, and proliferation in human adenocarcinoma colon cancer cells. J Agric Food Chem 60, 12443-12450.

95. Bienvenu JA, Monneret G, Gutowski MC, et al. (1998) Cytokine assays in human sera and tissues. Toxicology 129, 55-61.

96. Saemann MD, Bohmig GA, Osterreicher CH, et al. (2000) Anti-inflammatory effects of sodium butyrate on human monocytes: potent inhibition of IL-12 and up-regulation of IL-10 production. Faseb J 14, 2380-2382.

97. Leung CH, Lam W, Ma DL, et al. (2009) Butyrate mediates nucleotide-binding and oligomerisation domain (NOD) 2-dependent mucosal immune responses against peptidoglycan. Eur J Immunol 39, 3529-3537.

98. Blais M, Seidman EG \& Asselin C (2007) Dual effect of butyrate on IL-1beta-mediated intestinal epithelial cell inflammatory response. DNA Cell Biol 26, 133-147.

99. Romagnani P, Lasagni L, Annunziato F, et al. (2004) CXC chemokines: the regulatory link between inflammation and angiogenesis. Trends Immunol 25, 201-209.

100. Topping DL \& Clifton PM (2001) Short-chain fatty acids and human colonic function: roles of resistant starch and nonstarch polysaccharides. Physiol Rev 81, 1031-1064.

101. Krzystek-Korpacka M, Neubauer K, Berdowska I, et al. (2010) Impaired erythrocyte antioxidant defense in active inflammatory bowel disease: impact of anemia and treatment. Inflamm Bowel Dis 16, 1467-1475.

102. Zhu H \& Li YR (2012) Oxidative stress and redox signaling mechanisms of inflammatory bowel disease: updated experimental and clinical evidence. Exp Biol Med (Maywood) 237, 474-480.

103. Rezaie A, Parker RD \& Abdollahi M (2007) Oxidative stress and pathogenesis of inflammatory bowel disease: an epiphenomenon or the cause? Dig Dis Sci 52, 2015-2021.

104. Singh UP, Singh NP, Busbee B, et al. (2012) Alternative medicines as emerging therapies for inflammatory bowel diseases. Int Rev Immunol 31, 66-84.

105. Oz HS, Chen TS, McClain CJ, et al. (2005) Antioxidants as novel therapy in a murine model of colitis. $J$ Nutr Biochem 16, 297-304

106. Millar AD, Rampton DS, Chander CL, et al. (1996) Evaluating the antioxidant potential of new treatments for inflammatory bowel disease using a rat model of colitis. Gut 39, 407-415.

107. Tham DM, Whitin JC \& Cohen HJ (2002) Increased expression of extracellular glutathione peroxidase in mice with dextran sodium sulfate-induced experimental colitis. Pediatr Res 51, 641-646.
108. Te Velde AA, Pronk I, de Kort F, et al. (2008) Glutathione peroxidase 2 and aquaporin 8 as new markers for colonic inflammation in experimental colitis and inflammatory bowel diseases: an important role for $\mathrm{H}_{2} \mathrm{O}_{2}$ ? Eur J Gastroenterol Hepatol 20, 555-560.

109. Trivedi PP \& Jena GB (2012) Dextran sulfate sodiuminduced ulcerative colitis leads to increased hematopoiesis and induces both local as well as systemic genotoxicity in mice. Mutat Res 744, 172-183.

110. Kwon KH, Murakami A, Tanaka T, et al. (2005) Dietary rutin, but not its aglycone quercetin, ameliorates dextran sulfate sodium-induced experimental colitis in mice: attenuation of pro-inflammatory gene expression. Biochem Pharmacol 69, 395-406.

111. Camuesco D, Comalada M, Concha A, et al. (2006) Intestinal anti-inflammatory activity of combined quercitrin and dietary olive oil supplemented with fish oil, rich in EPA and DHA (n-3) polyunsaturated fatty acids, in rats with DSS-induced colitis. Clin Nutr 25, 466-476.

112. Villegas I, Alarcon de la Lastra C, Orjales A, et al. (2003) A new flavonoid derivative, dosmalfate, attenuates the development of dextran sulphate sodium-induced colitis in mice. Int Immunopharmacol 3, 1731-1741.

113. Melgar S, Karlsson L, Rehnstrom E, et al. (2008) Validation of murine dextran sulfate sodium-induced colitis using four therapeutic agents for human inflammatory bowel disease. Int Immunopharmacol 8, 836-844.

114. Islam MS, Murata T, Fujisawa M, et al. (2008) Antiinflammatory effects of phytosteryl ferulates in colitis induced by dextran sulphate sodium in mice. BrJPharmacol 154, 812-824

115. Ruiz PA, Braune A, Holzlwimmer G, et al. (2007) Quercetin inhibits TNF-induced NF-kappaB transcription factor recruitment to proinflammatory gene promoters in murine intestinal epithelial cells. J Nutr 137, 1208-1215.

116. Kim H, Kong H, Choi B, et al. (2005) Metabolic and pharmacological properties of rutin, a dietary quercetin glycoside, for treatment of inflammatory bowel disease. Pharm Res 22, 1499-1509.

117. Deguchi Y, Andoh A, Inatomi O, et al. (2007) Curcumin prevents the development of dextran sulfate sodium (DSS)-induced experimental colitis. Dig Dis Sci $\mathbf{5 2}$, 2993-2998.

118. Akiyama S, Nesumi A, Maeda-Yamamoto M, et al. (2012) Effects of anthocyanin-rich tea 'Sunrouge' on dextran sodium sulfate-induced colitis in mice. Biofactors $\mathbf{3 8}$, 226-233

119. Piberger H, Oehme A, Hofmann C, et al. (2011) Bilberries and their anthocyanins ameliorate experimental colitis. Mol Nutr Food Res 55, 1724-1729.

120. Kidd VJ (1998) Proteolytic activities that mediate apoptosis. Annu Rev Physiol 60, 533-573.

121. Goretsky T, Dirisina R, Sinh P, et al. (2012) p53 mediates TNF-induced epithelial cell apoptosis in IBD. Am J Pathol 181, 1306-1315.

122. Rieder F, Karrasch T, Ben-Horin S, et al. (2012) Results of the 2nd scientific workshop of the ECCO (III): basic mechanisms of intestinal healing. J Crohns Colitis 6, 373-385.

123. Iizuka M \& Konno S (2011) Wound healing of intestinal epithelial cells. World J Gastroenterol 17, 2161-2171.

124. Ho SB, Dvorak LA, Moor RE, et al. (2006) Cysteine-rich domains of muc3 intestinal mucin promote cell migration, inhibit apoptosis, and accelerate wound healing. Gastroenterology 131, 1501-1517. 
125. Deshpande SS, Sathe SK \& Salunkhe DK (1984) Dry beans of Phaseolus: a review. Part 3. Crit Rev Food Sci Nutr 21, 137-195.

126. Kumar S, Verma AK, Das M, et al. (2013) Clinical complications of kidney bean (Phaseolus vulgaris L.) consumption. Nutrition 29, 821-827.

127. Zhu Z, Jiang W \& Thompson HJ (2012) Edible dry bean consumption (Phaseolus vulgaris L.) modulates cardiovascular risk factors and diet-induced obesity in rats and mice. Br J Nutr 108, Suppl. 1, S66-S73.

128. Rondini EA \& Bennink MR (2012) Microarray analyses of genes differentially expressed by diet (black beans and soy flour) during azoxymethane-induced colon carcinogenesis in rats. J Nutr Metab 2012, 351796.

129. Hughes JS, Ganthavorn C \& Wilson-Sanders S (1997) Dry beans inhibit azoxymethane-induced colon carcinogenesis in F344 rats. J Nutr 127, 2328-2333.

130. Key FB, McClean D \& Mathers JC (1996) Tissue hypertrophy and epithelial proliferation rate in the gut of rats fed on bread and haricot beans (Phaseolus vulgaris). Br J Nutr 76, 273-286.

131. Kumar V, Sinha AK, Makkar HP, et al. (2012) Dietary roles of non-starch polysaccharides in human nutrition: a review. Crit Rev Food Sci Nutr 52, 899-935.

132. Hou J \& Sellin J (2010) Diet, nutrition and inflammatory bowel disease. Therapy 7, 179-189.

133. Nanau RM \& Neuman MG (2012) Nutritional and probiotic supplementation in colitis models. Dig Dis Sci 57, 2786-2810.

134. Abia R, Buchanan CJ, Saura-Calixto F, et al. (1993) Structural changes during the retrogradation of legume starches modify the in vitro fermentation. J Agric Food Chem 41, 1856-1863.

135. Jenkins DJ, Kendall CW, Augustin LS, et al. (2012) Effect of legumes as part of a low glycemic index diet on glycemic control and cardiovascular risk factors in type 2 diabetes mellitus: a randomised controlled trial. Arch Intern Med 172, 1653-1660. 